\title{
Discrimination of ablation, shielding, and interface layer effects on the steady-state formation of persistent bubbles under liquid flow conditions during laser synthesis of colloids
}

\author{
Mark-Robert Kalus $^{1} \cdot$ Riskyanti Lanyumba $^{1} \cdot$ Stephan Barcikowski $^{1}$ (D) Bilal Gökce ${ }^{1,2}$ (D) \\ Received: 16 December 2020 / Accepted: 8 February 2021 / Published online: 15 March 2021 \\ (C) The Author(s) 2021
}

\begin{abstract}
Over the past decade, laser ablation in liquids (LAL) was established as an innovative nanoparticle synthesis method obeying the principles of green chemistry. While one of the main advantages of this method is the absence of stabilizers leading to nanoparticles with "clean" ligand-free surfaces, its main disadvantage is the comparably low nanoparticle production efficiency dampening the sustainability of the method and preventing the use of laser-synthesized nanoparticles in applications that require high amounts of material. In this study, the effects of productivity-dampening entities that become particularly relevant for LAL with high repetition rate lasers, i.e., persistent bubbles or colloidal nanoparticles (NPs), on the synthesis of colloidal gold nanoparticles in different solvents are studied. Especially under batch ablation conditions in highly viscous liquids with prolonged ablation times both shielding entities are closely interconnected and need to be disentangled. By performing liquid flow-assisted nanosecond laser ablation of gold in liquids with different viscosity and nanoparticle or bubble diffusivity, it is shown that a steady-state is reached after a few seconds with fixed individual contributions of bubble- and colloid-induced shielding effects. By analyzing dimensionless numbers (i.e., Axial Peclet, Reynolds, and Schmidt) it is demonstrated how these shielding effects strongly depend on the liquid's transport properties and the flow-induced formation of an interface layer along the target surface. In highly viscous liquids, the transport of NPs and persistent bubbles within this interface layer is strongly diffusion-controlled. This diffusion-limitation not only affects the agglomeration of the NPs but also leads to high local densities of NPs and bubbles near the target surface, shielding up to $80 \%$ of the laser power. Hence, the ablation rate does not only depend on the total amount of shielding matter in the flow channel, but also on the location of the persistent bubbles and NPs. By comparing LAL in different liquids, it is demonstrated that 30 times more gas is produced per ablated amount of substance in acetone and ethylene glycol compared to ablation in water. This finding confirms that chemical effects contribute to the liquid's decomposition and the ablation yield as well. Furthermore, it is shown that the highest ablation efficiencies and monodisperse qualities are achieved in liquids with the lowest viscosities and gas formation rates at the highest volumetric flow rates.
\end{abstract}

Keywords Laser ablation in liquids · Metal nanoparticles $\cdot$ Liquid flow · Gas formation · Liquid viscosity

\section{Introduction}

Stephan Barcikowski

stephan.barcikowski@uni-due.de

1 Technical Chemistry I, Center for Nanointegration Duisburg-Essen (CENIDE), University of Duisburg-Essen, 45141 Essen, Germany

2 Materials Science and Additive Manufacturing, School of Mechanical Engineering and Safety Engineering, University of Wuppertal, 42119 Wuppertal, Germany

Nowadays, nanotechnology is a rapidly developing field with increasing demand and high future potential for applications in areas such as biomedicine [1,2], optics [3, 4], or catalysis $[5,6]$. The production of nanomaterials typically takes place via wet-chemical $[7,8]$, gas phase $[9,10]$, or solid-state processes [11, 12]. However, nanoparticles (NPs) produced by these methods are often subject to agglomeration and aggregation effects if no further stabilizing agents are added to the process [13]. The use of stabilizers is unwanted, in areas such as catalysis or biomedicine, where strict requirements are placed on the properties of the NPs, such as their size and 
purity [14]. Additionally, it is sometimes desired to have the NPs in organic liquids, for example, for in-situ preparations of nanocomposites [15-17], useful as medical devices like antimicrobial catheters $[18,19]$. However, the synthesis of NPs in organic liquids is difficult to realize with conventional methods without stabilizing ligands [20].

In this context, laser ablation in liquids (LAL) represents a green [21, 22], cost-effective [23] and scalable [24, 25] alternative that provides access to a variety of high-purity [26] nanomaterials such as metals [27-29], alloys [30, 31] or oxides [32-34], available in both aqueous [27, 28, 35] and organic media [36-38]. Their application potential is manifold and has already found its way into fields such as biomedicine $[30,39]$, catalysis [40-45], solar energy [46] or 3D printing [47-49]. Even though the production of these materials is already possible on the gram-scale [24, 25], high-power and expensive laser systems are required. Therefore, numerous approaches aimed to optimize the NP ablation efficiency based on parameters that are independent of investment costs, including target geometry optimization [50-52], scanning strategy [24, 25, 53], and liquid height adjustment [54, 55].

Furthermore, special ablation chambers have been designed, enabling the production of NPs under batch [56] and liquid flow conditions [24, 25]. The production of NPs in semi-batch or batch chambers can be performed with or without stirring the liquid [56]. This method is particularly useful for application fields where small amounts and high concentrations of colloids are required. However, since long ablation times are needed to achieve high NP concentrations, the NP production rate decreases over time due to increasing colloidinduced shielding effects [57, 58]. Additionally, the probability of NP post-irradiation effects [59] increases, leading to the formation of large quantities of nanobubbles [59-62]. This way, the reproducibility and quality of the final products suffer as fragmentation [63-65] and melting [66, 67] of the NPs alters the size distribution of the final NPs.

Furthermore, LAL induces the liquid's decomposition and the formation of so-called persistent bubbles [59, 68-70]. These bubbles represent a permanent shielding entity sticking to the bulk target surface, screening the laser beam, and negatively affecting NP production rate. For this reason, LAL is often performed under dynamic flow conditions by continuously overflowing the target substrate $[24,25,56]$. This way, local NP accumulation can be significantly reduced, resulting in increased NP production rate with increasing flow rate $[25$, $33,56,71]$. Since persistent bubbles absorb, reflect, and defocus the laser beam, better underwater laser micromachining results can also be achieved using a liquid flow [72-74].

Although initial work has been carried out to investigate the dynamic features of the bubbles that form during laser cutting of silicon in flowing water [72], such studies have not yet been performed for liquid flow assisted LAL.
Moreover, the influence of other liquids besides water on LAL-induced bubble formation has so far only been investigated for batch conditions. In this context, it was shown that persistent bubbles form that shield up to $65 \%$ of the liquid cross-section depending on liquid viscosity, affecting production rate and reproducibility of laser-generated NPs [68]. Moreover, Hupfeld et al. observed that cavitation bubbles with quite non-symmetric, oblate-shaped geometries form in highly viscous polyalphaolefin (PAO), whose collapse leads to long-lasting, persistent bubbles [75]. These studies underline the importance of liquid viscosity for bubble formation and ablation efficiency during LAL in stationary liquids. However, it is still unclear how the liquid viscosity affects the bubble and NP formation during liquid flow-assisted LAL. It is undisputed that an interface layer forms along the target surface under these ablation conditions [76], possibly influencing the removal of the bubbles and NPs from the ablation area. Unfortunately, its influence has hardly been discussed in LAL literature so far and therefore requires more attention.

For closing these evident knowledge gaps and increasing the efficiency of this sustainable synthesis method, the influence of a liquid flow on the formation of NPs and persistent bubbles during ns-ablation in liquids of different viscosity (water, acetone, and ethylene glycol) is investigated in this study and correlated with the mass ablation and gas formation rates. In the first section, the steady-state formation of NPs and persistent bubbles are studied depending on the liquid's volumetric flow rate. Furthermore, the interface layer that forms along the target surface under flow conditions is characterized to understand the influence of flow dynamics on the removal of NPs and persistent bubbles from the ablation zone depending on the liquid's viscosity. In the second section, the persistent bubbles are systematically analyzed and quantified to determine their shielding capacity. The shielding effects are correlated with the mass ablation rates in the third section of this work and linked with the NPs' properties. The fourth section concludes this study by evaluating the gas formation efficiencies as a function of liquid selection, shielding effects, and mass ablation rates.

\section{Materials and methods}

The experimental setup for performing LAL and quantifying the gas volume in a liquid flow is demonstrated in Fig. 1.

For all experiments, an ablation flow chamber (h: $6 \mathrm{~mm}$, w: $6 \mathrm{~mm}, 1: 18 \mathrm{~mm}$ ) made of anodized aluminum was used. Sideobservation windows were integrated into the chamber to monitor the bubble formation. A gold target $(99.99 \%, 10 \times$ $5 \times 0.5 \mathrm{~mm}$, Allgemeine Gold) was used for ablation and placed inside the ablation chamber. The thickness of the liquid layer was $6 \mathrm{~mm}$. The experiments were performed in 


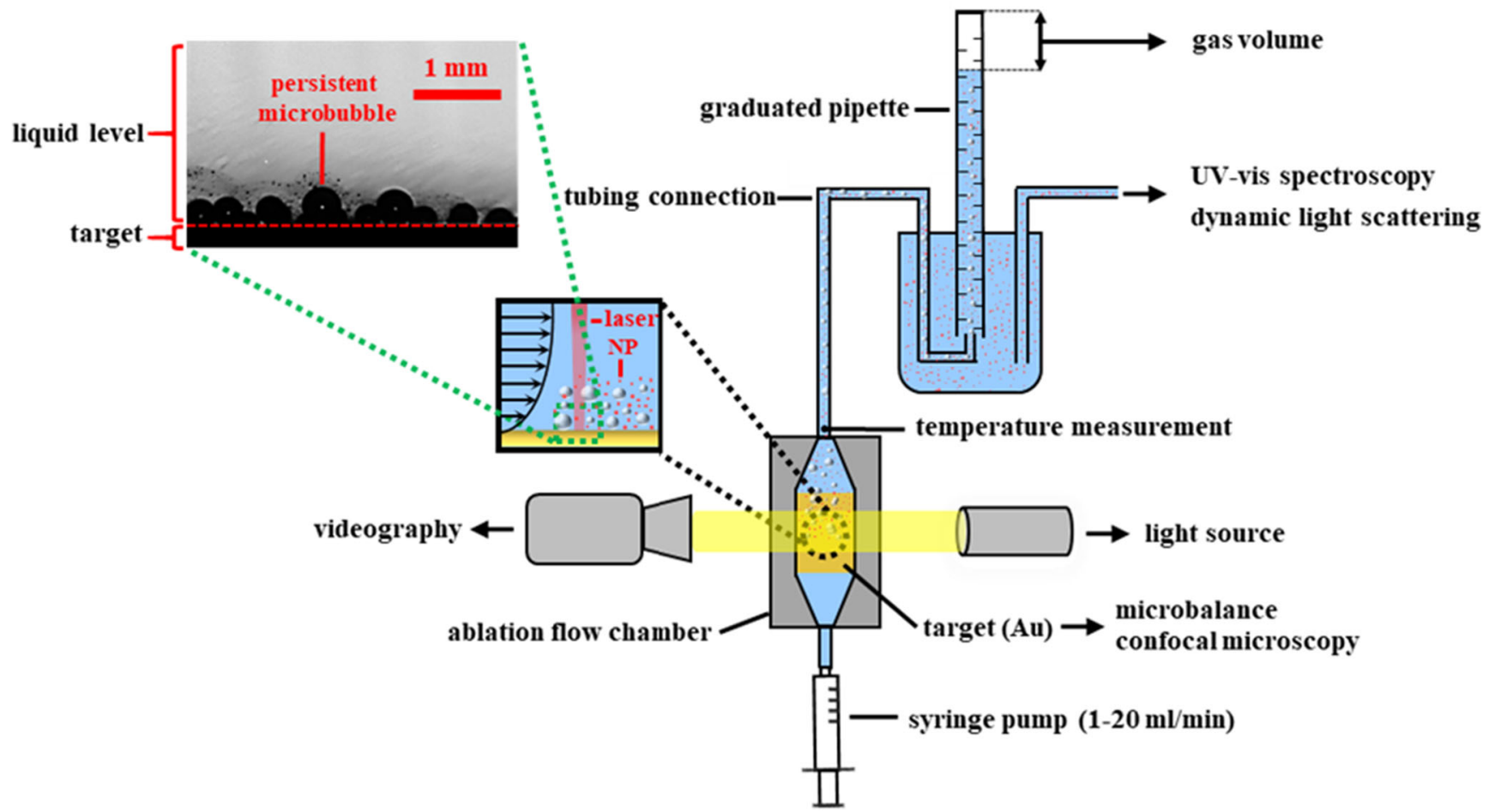

Fig. 1 Experimental setup for measuring the gas volume and bubble dynamics during LAL in water, acetone, and ethylene glycol performed in a custommade ablation flow chamber

deionized water $\left(18.2 \mathrm{M} \Omega \mathrm{cm}\right.$ at $25^{\circ} \mathrm{C}$ ), acetone (VWR Prolabo, $\geq 99.0 \%$ ), and ethylene glycol (Sigma-Aldrich, 99.8\%) as carrier liquid. For ensuring a constant, pulsationfree volumetric flow rate, a syringe pump was used. The syringe was connected with the ablation chamber's inlet by a tube made of polytetrafluoroethylene (PTFE). A tube made of PTFE was also connected to the outlet of the ablation chamber. The other end of the tube was inserted into a graduated pipette placed in a beaker filled with liquid.

LAL was performed using an Nd:YAG ns-laser (Rofin Powerline E20). The laser wavelength was $1064 \mathrm{~nm}$, and the pulse length $8 \mathrm{~ns}$. A repetition rate of $15 \mathrm{kHz}$ was used during all the experiments delivering a pulse energy of $0.33 \mathrm{~mJ}$. The laser beam was guided along the target surface with a scan speed of $2 \mathrm{~m} / \mathrm{s}$ using a galvanometer scanner (SCANcube 10, Scanlab). Therefore, a spiral pattern with a diameter of $5 \mathrm{~mm}$ was used. The laser beam was focused on the target through an F-theta lens with a focal length of $100 \mathrm{~mm}$, resulting in an average spot size of $40 \pm 10 \mu \mathrm{m}$ in the focal position (measured in air), which corresponds to a nominal laser fluence of $25.9 \mathrm{~J} / \mathrm{cm}^{2}$ (details on the laser fluence are given in Fig. 12). Focus adjustment was performed for every liquid by varying the working distance between the F-theta lens and the ablation target in a range between $-1 \mathrm{~mm}$ and $1 \mathrm{~mm}$ (Fig. 2).

The produced colloids were characterized by UV-Vis spectroscopy. The extinction of the colloids at a wavelength of $380 \mathrm{~nm}$ is proportional to the Au NP mass concentration and was plotted against the working distance. A negative/positive working distance corresponds to the focus placed into the liquid/behind the target. A working distance of zero corresponds to the highest ablation efficiency. Ns-LAL was performed in each liquid for 10 min by varying the volumetric flow rate in steps of $1,5,10,15$, and $20 \mathrm{ml} / \mathrm{min}$. The ablated mass was measured gravimetrically after the ablation process using a microbalance (Pesa Waagen $\mathrm{GmbH}$ ).

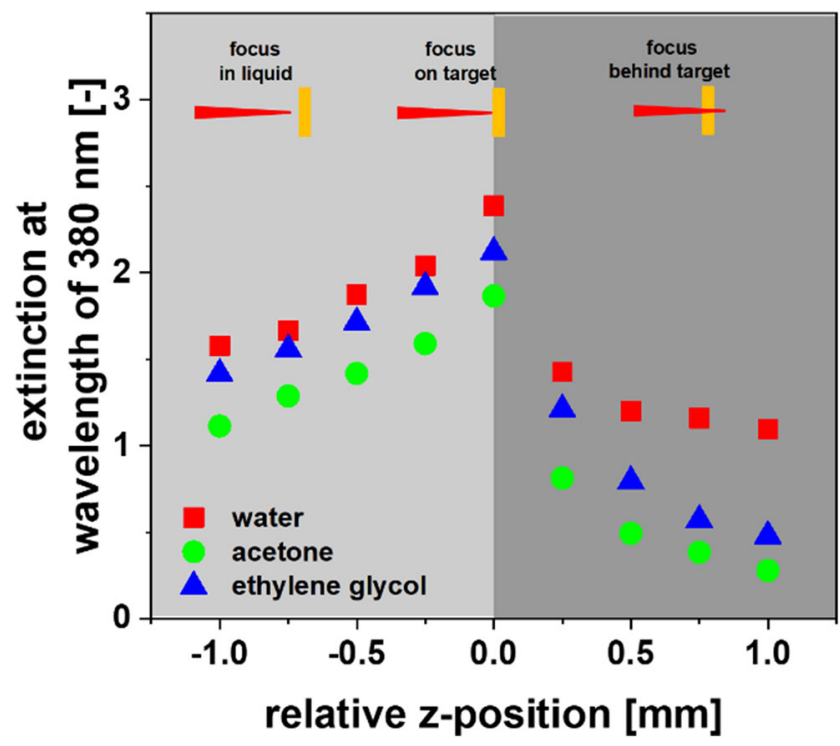

Fig. 2 Focus adjustment for ns-LAL of Au performed in water, acetone, and ethylene glycol as a function of the extinction at a wavelength of $380 \mathrm{~nm}$ (proportional to the NP mass concentration). The maximum was normalized to the relative z-position 0 
The gas volume was determined by the liquid displacement method. Gases produced during the ablation process were continuously transported through the tubes into the liquidfilled graduated pipette, leading to the liquid's displacement. By recording the amount of displaced liquid, the volume of formed gas was obtained. The liquid flow was maintained for several minutes after the ablation process was stopped to ensure the quantitative measurement of the gases without residues in the chamber or tubes. The gas cross-section imaging was recorded with the aid of a videography system described in [68]. The results were evaluated with ImageJ and further processed with OriginPro (version 2018b).

For further analysis, the temperature was measured over ablation time. Therefore, a thermocouple was integrated at the outlet of the ablation chamber. Furthermore, the laser fluence shielded by the produced colloids was measured ex-situ. For this purpose, the produced colloids were filled into a glass cuvette. By placing a power meter (Coherent Inc., FieldMax > IITO) behind the glass cuvette and guiding the laser beam through the cell and colloids, the decrease of the pulse energy induced by the shielding of the NPs was determined. The colloids were further characterized by measuring their size using dynamic light scattering (Nicomp 380 DLS-ZLS). Besides, the ablation profile on the Au target was determined after laser processing using confocal 3D microscopy (Nanofocus).

\section{Results and discussion}

\section{Steady-state formation of nanoparticles and persistent bubbles depending on the liquid flow dynamics}

Recent studies have shown that NP productivity in LAL strongly depends on the liquid's viscosity, which was explained by the formation of persistent bubbles and their viscosity-dependent dwell time in the ablation zone $[68,75]$. Furthermore, the produced NPs can act as shielding entities and reduce the ablation efficiency [57-59]. These two limitations are particularly pronounced during batch processing. Here, the NP mass concentration increases with increasing ablation time and persistent bubbles accumulate within the liquid or stick to the target surface. Liquid flow setups [25, $33,56,71]$ are typically used to overcome these limitations and improve the removal of persistent bubbles and NPs from the ablation area. In this study, liquid flow-assisted ns-LAL of $\mathrm{Au}$ was performed in three different liquids, acetone, water, and ethylene glycol, covering different liquid viscosities of $1.00,0.33$, and $20.81 \mathrm{mPa} \cdot \mathrm{s}$ at $293 \mathrm{~K}$. Fig. 3a-c shows an exemplary picture series for the processes occurring on the millisecond time regime during ns-LAL of Au in these liquids at an exemplary volumetric flow rate of $1 \mathrm{ml} / \mathrm{min}$.
As evident in the picture series, shortly after the arrival of the first laser pulses, persistent bubbles are formed. Gas chromatography measurements have shown that these bubbles contain permanent gases $\left(\mathrm{H}_{2}, \mathrm{O}_{2}\right.$ for ns-ablation in water, and in the case of ns-ablation in glycols, additional $\mathrm{CH}_{4}, \mathrm{CO}, \mathrm{CO}_{2}, \mathrm{C}_{2} \mathrm{H}_{4}$, and $\mathrm{C}_{2} \mathrm{H}_{2}$ ) [68]. In addition to persistent bubbles, the formation of a dark cloud of NPs in the liquid is observed. The darkening is faster and stronger in water and acetone than in ethylene glycol. In the latter case, such a cloud of NPs is hardly visible and more located towards the target surface.

The liquid's darkening was evaluated by measuring the cross-sectional light attenuation of the individual picture frames for each liquid and volumetric flow rate depending on time (Fig. 3d-f). Of course, this procedure represents only a rough estimation since the darkening of the liquid depends on the optical properties (e.g., transmission, absorption, and refraction behavior) of the colloidal system and persistent bubbles and the experimental alignment of the light source to the ablation chamber and the camera system. For a better comparison of the results, the cross-sectional light attenuation was normalized. A normalized cross-sectional light attenuation of $0 \%$ corresponds to the pure liquid. Higher percentages are due to the presence of persistent bubbles and NPs. The results can be described by a hill function leading to steady-state conditions (defined as the time after which $90 \%$ of the maximum normalized cross-sectional light attenuation is achieved) after a specific mixing time. Hence, this procedure gives a rough idea about the mixing behavior (the time point when steady-state conditions are reached) inside the ablation chamber as a function of the ablation time and volumetric flow rate.

For ns-LAL of $\mathrm{Au}$ in water, a clear dependence on the volumetric flow rate can be observed. For the lowest volumetric flow rate of $1 \mathrm{ml} / \mathrm{min}$, steady-state conditions are reached after about two seconds. The time for reaching the steady-state decreases steadily with increasing volumetric flow rate until half a second at $20 \mathrm{ml} / \mathrm{min}$ (Fig. 3d). For ns-LAL of Au in acetone, steady-state conditions are reached after one second, independent of the volumetric flow rate (Fig. 3e). However, for ns-LAL of $\mathrm{Au}$ in ethylene glycol, a normalized crosssectional light attenuation of $100 \%$ is never achieved. Typical values are about $10 \%$, with steady-state conditions being reached after about one second if volumetric flow rates of $10 \mathrm{ml} / \mathrm{min}$ and more are used (see Fig. 3f). Consequently, mixing persistent bubbles and NPs within the entire chamber volume is less efficient in ethylene glycol.

For further discussion, the diffusion coefficients $(D)$ of the NPs and persistent bubbles were calculated according to the Stokes-Einstein equation [77].

$D=\frac{k_{B} \cdot T}{6 \cdot \pi \cdot \eta \cdot R_{h y d}}$ 


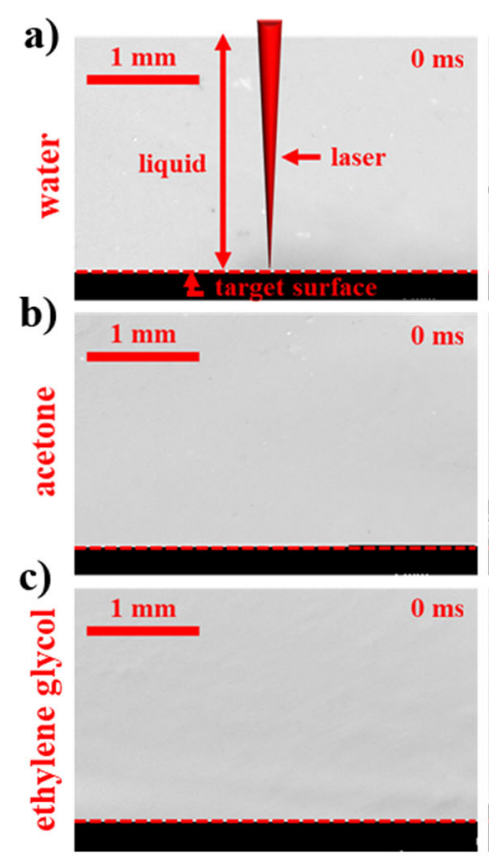

d)

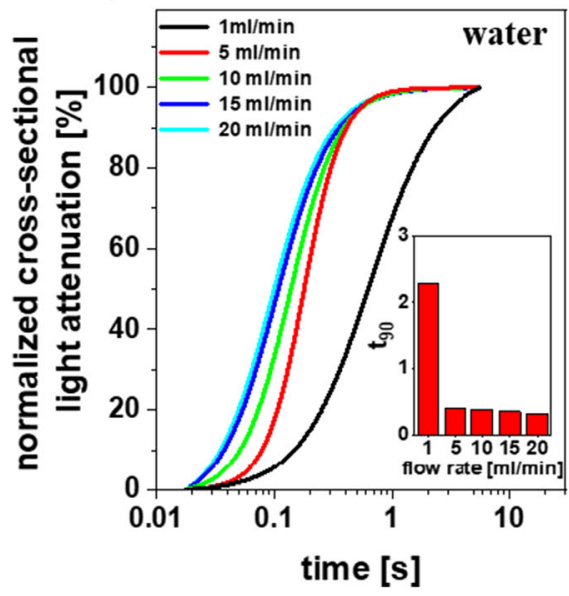

Fig. 3 a-c Exemplary images taken for water, acetone, and ethylene glycol as a function of time showing the persistent bubble formation process and mixing of NPs in the liquid at a volumetric flow rate of $1 \mathrm{ml} / \mathrm{min}$. d-f Cross-sectional light attenuation normalized to maximum shielding during LAL in water, acetone, and ethylene glycol as a function

Here, $k_{B}$ represents the Boltzmann constant $\left(1.38 \cdot 10^{-23} \mathrm{~J} /\right.$ $\mathrm{K})$, while $T$ is the temperature and $\eta$ the liquid's dynamic viscosity. $R_{h y d}$ stands for the radius of the bubbles extracted from the shadowgraphy images or the hydrodynamic radius of the NPs, which was measured by DLS (compare Fig. 11c-e). Please note that the calculations in following are meant to be a first approximation for the comparison between nanometersized spherical solid particles and micrometer-sized spherical persistent bubbles. Due to the size difference between these entities, the constants determined by the Eq. 1 (as well as Eqs. 2-4 introduced in the next sections) have a difference of 2-4 orders of magnitude and are used for a relative comparison between these entities generated in different solvents. The

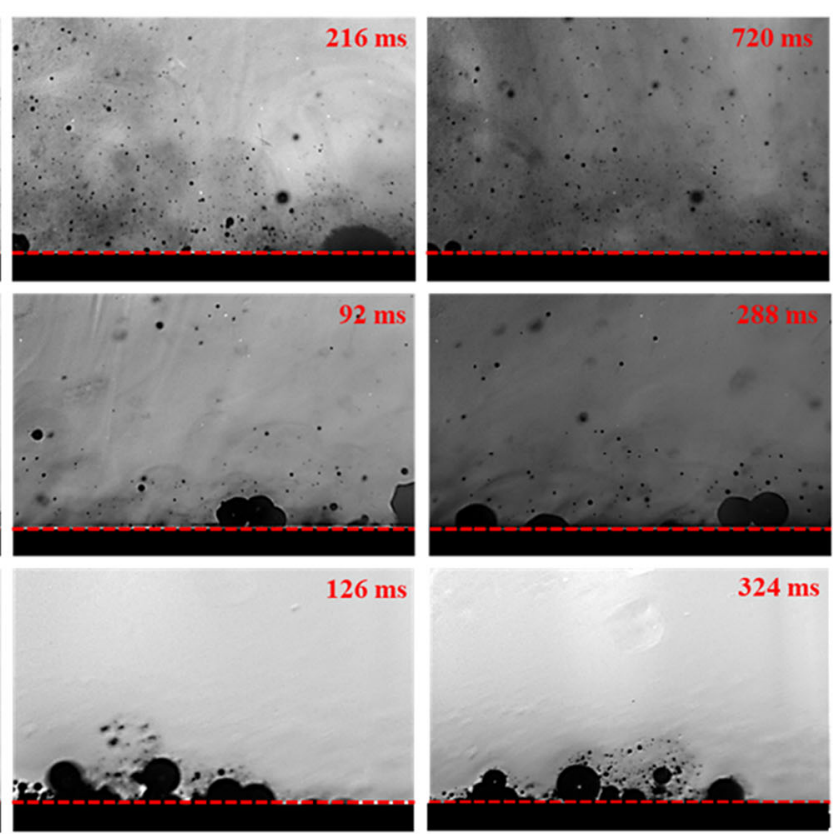

f)

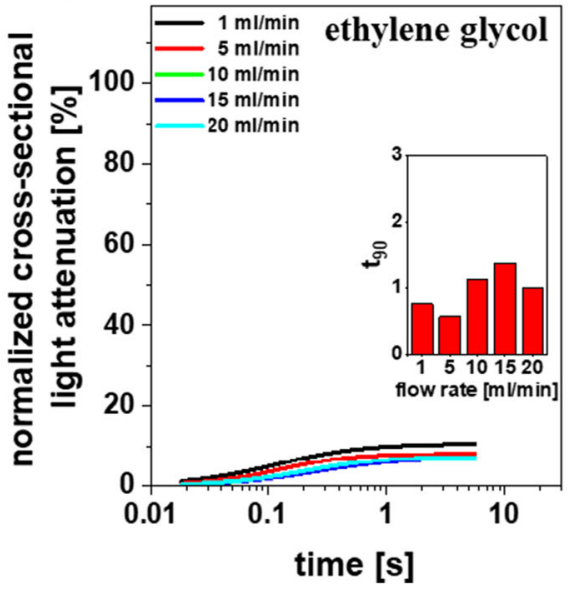

of time and different volumetric flow rates. The specific times, after which $90 \%\left(t_{90}\right)$ of the cross-sectional light attenuation was reached, are included as inserts to provide reference values for the time until steadystate conditions are reached

performed comparisons would be lacking for a case in which the particles and the bubbles have similar sizes.

Since the colloid is heated during LAL [78], the temperature dependency of the diffusion coefficient needs to be considered. For this reason, the temperature increase of the colloid produced during ablation of $\mathrm{Au}$ in water, acetone, and ethylene glycol was measured at the outlet of the ablation chamber as a function of the ablation time. The results of these measurements are displayed in Fig. 4a and b for volumetric flow rates of $1 \mathrm{ml} / \mathrm{min}$ and $20 \mathrm{ml} / \mathrm{min}$.

For a volumetric flow rate of $1 \mathrm{ml} / \mathrm{min}$, the average heating rate is $0.9^{\circ} \mathrm{C} / \mathrm{min}$, and the maximum colloid temperature is $38{ }^{\circ} \mathrm{C}$. For a higher volumetric flow rate of $20 \mathrm{ml} / \mathrm{min}$, the 
a)
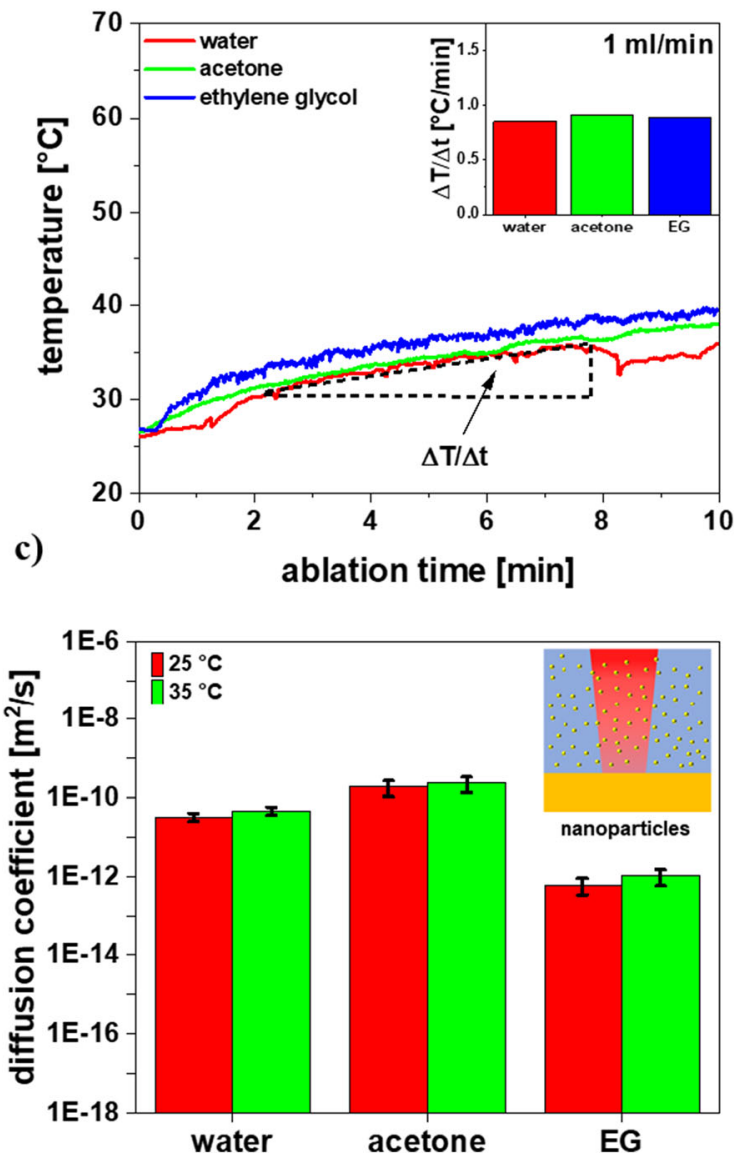

Fig. 4 a,b Colloid temperature increase as a function of ablation time for ns-LAL of $\mathrm{Au}$ in water, acetone, and ethylene glycol at volumetric flow rates of 1 and $20 \mathrm{ml} / \mathrm{min}$. The inserts show the heating rate derived from the slope of the linear fit within an ablation time of 2-8 min. c,d Diffusion

temperature increase is lower, resulting in a maximum colloid temperature of $29^{\circ} \mathrm{C}$. Additionally, the heating rates are significantly lower $\left(0.2-0.3{ }^{\circ} \mathrm{C} / \mathrm{min}\right)$, indicating that the faster liquid exchange reduces the heat accumulation within the colloid. Note that the colloids' absolute temperatures are the highest in ethylene glycol, followed by acetone and water. The different colloid temperatures are probably caused by the NP-induced shielding effects, contributing to the liquid's heating. As discussed later in more detail, these shielding effects are the highest in ethylene glycol (see Fig. 12).

For calculating the diffusion coefficient, an average liquid temperature of $35^{\circ} \mathrm{C}$ was considered for a volumetric flow rate of $1 \mathrm{ml} / \mathrm{min}$. Hence, also the liquid viscosity at this given temperature was used [79-81]. As displayed in Fig. 4c, the diffusion coefficients are the highest for NPs produced in acetone $\left(2.4 \pm 1.0 \cdot 10^{-10} \mathrm{~m}^{2} / \mathrm{s}\right)$, followed by water $(4.7 \pm 1.1$. $\left.10^{-11} \mathrm{~m}^{2} / \mathrm{s}\right)$ and ethylene glycol $\left(1.0 \pm 0.5 \cdot 10^{-12} \mathrm{~m}^{2} / \mathrm{s}\right)$. Since the liquid temperature decreases by about $10^{\circ} \mathrm{C}$ with increasing volumetric flow rate (Fig. $4 \mathrm{~b}$ ), the diffusion coefficients are also 20-40\% lower (Fig. 4c). However, the general trend between the individual liquids remains the same.
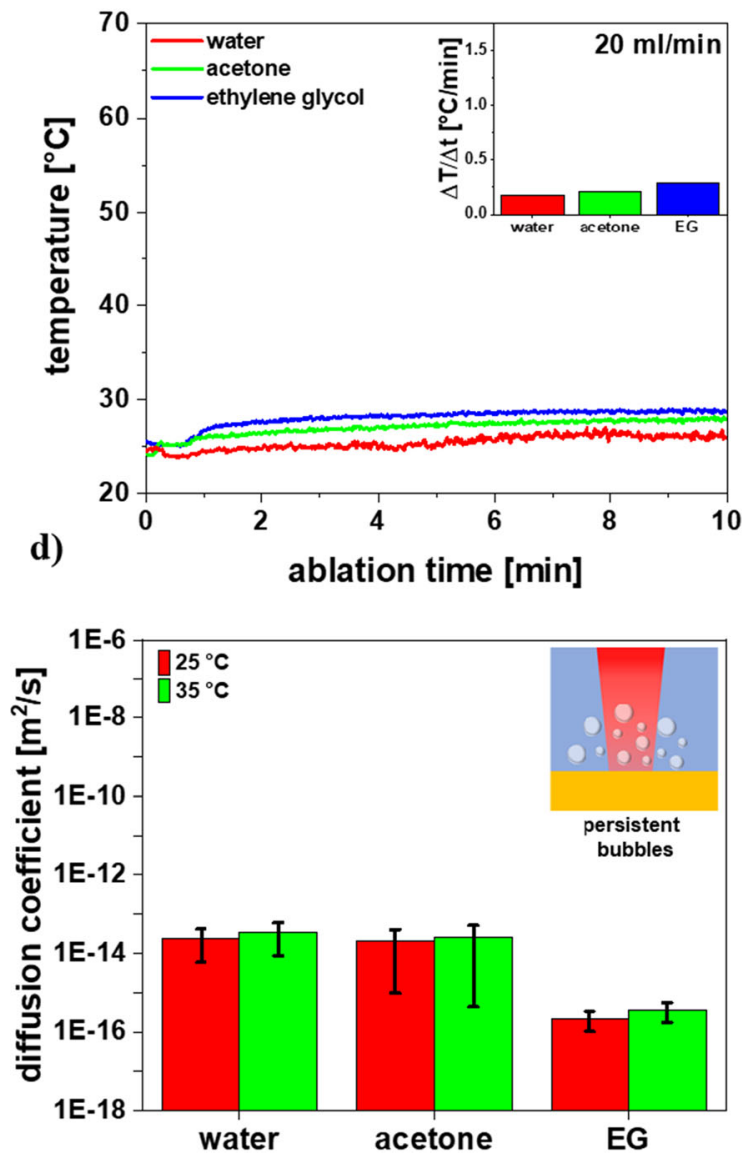

coefficients were calculated using the Stoke-Einstein equation by considering the average diameter of the NPs and persistent bubbles and temperatures of $25^{\circ} \mathrm{C}$ and $35^{\circ} \mathrm{C}$

The diffusion coefficients for the persistent bubbles (Fig. 4d) were calculated based on their average diameters extracted from the cross-sectional images (the individual bubble size characteristics are discussed in Fig. 7d-f). The trends are similar to NPs with absolute values of $2.6 \pm 2.5 \cdot 10^{-14} \mathrm{~m}^{2} / \mathrm{s}$ for acetone, $3.5 \pm 2.6 \cdot 10^{-14} \mathrm{~m}^{2} / \mathrm{s}$ for water, and $3.6 \pm 1.9$. $10^{-16} \mathrm{~m}^{2} / \mathrm{s}$ for ethylene glycol. As expected, these values are several orders lower than the diffusion coefficients calculated for the NPs due to the significant differences in their sizes. The low diffusibility in ethylene glycol is probably the reason why the persistent bubbles and NPs remain very close to the target surface. In contrast, smaller bubbles are found far away from the target surface in water and acetone. However, their origin is unsure and could be attributed to gas formation effects induced by post-irradiation of the NPs [59, 82]. In this context, Dittrich et al. recently provided indications that NPs trapped in the stationary liquid layer which is formed along the target surface during liquid flow conditions (discussed in more detail in the following section of this work) could be the source of additional gas formation cross-effects when post-irradiated by subsequent laser pulses [83]. 
As pointed out before, when working in liquid flow, an interface layer is formed along the target surface, which characteristics strongly depend on the flow-field conditions and the liquid viscosity $[76,84]$. Friction and adhesive forces between the target surface and the liquid layers cause the shearing of the liquid, resulting in a flow velocity gradient. Liquid layers close to the target surface move slower if the adhesive forces between the liquid elements and the bulk surface are larger than the cohesive forces between them. The interface layer thickness is then defined as the distance at which $99 \%$ of the main flow velocity is reached $[76,84]$. Note that the flow in the interface layer can be laminar or turbulent $[85,86]$. The type of flow can be estimated by calculating the Reynolds number $(R e)$ according to eq. 2 [87], which describes the ratio between inertia and viscous forces in the bulk-liquid system.

$R e=\frac{\mathrm{v}_{0} \cdot l}{v}$

Here, $v_{0}$ represents the main flow velocity, which can be calculated by dividing the volumetric flow rate by the chamber's flow-cross section. Furthermore, the kinematic viscosity $\nu$ of the corresponding liquid and the characteristic travel distance $l$ (the ablated bulk target's length was used as reference) need to be considered. The results are presented in Fig. 5a.

The lowest $R e$ of 1 to 5 are obtained for ethylene glycol as liquid with the highest viscosity used in the experiments. For water, which has a 30 times lower viscosity than ethylene glycol, significantly larger $R e$ in the range of 5 to 92 were calculated. For low-viscosity acetone, the $R e$ is even twice as large compared to water covering values from 11 to 220 . Considering the criterion for the transition into the turbulent regime under the assumption of a longitudinal flow along a bulk plate $\left(R e_{c r i t}<5 \cdot 10^{5}\right)$ [88], a laminar flow forms for all investigated liquids and flow rates, what is probably a general characteristic of liquid flow-assisted LAL.

Hupfeld et al. additionally calculated the Weber (We) and Capillary $(\mathrm{Ca})$ number beside $\mathrm{Re}$ to account for the competition between viscous forces, surface tension, and inertia, affecting the dynamics and shape of the cavitation bubble, including the interface layer height [75]. Note that the calculation of these numbers refers to the velocity of the fast-expanding cavitation bubble, which is about 2000 times higher than the main liquid flow velocity. Hence, We and $\mathrm{Ca}$ are of minor importance for the persistent bubbles and NPs under the prevailing experimental conditions. Nevertheless, the cavitation bubble dynamics may influence the flow characteristics during liquid flowassisted LAL but are out of this study's scope.

In the next step, the axial Peclet number $\left(P e_{a x}\right)$ was calculated, which is defined as the ratio of convective to diffusive transport phenomena in axial direction according to eq. 3 .

$P e_{a x}=\frac{h \cdot v_{0}}{D}$
Here, $h$ stands for the liquid layer's height, while $v_{0}$ represents the velocity of the main flow and $D$ the diffusion coefficient of the NPs and persistent bubbles (extracted from Fig. $4 \mathrm{c}$ and d). $P e_{a x}$ was calculated for the NPs and the persistent bubbles and plotted against $R e$, as shown in Fig. $5 \mathrm{~b}$ and c. Generally, for both NPs and persistent bubbles, $P e_{a x}$ increases with increasing $R e$, indicating a greater importance of convective transport phenomena at high liquid flow velocities. Within the individual liquids, the $P e_{a x}$ are the highest for NPs produced in ethylene glycol ranging from $4.5 \pm 0.1 \cdot 10^{6}$ to $9.0 \pm 0.1 \cdot 10^{7}$. In water, the $P e_{a x}$ values are 50 times lower compared to ethylene glycol $\left(0.9 \pm 0.2 \cdot 10^{5}\right.$ to $\left.1.7 \pm 0.4 \cdot 10^{6}\right)$, while in acetone, they are even 300 times lower $\left(1.5 \pm 0.1 \cdot 10^{4}\right.$ to $3 \pm 0.1 \cdot 10^{5}$ ). The same trend can be observed for persistent bubbles with $P e_{a x}$ values about 1000-10,000 times higher than for the NPs (Fig. 4d). The differences in the $P e_{a x}$ can be assigned to the different diffusion coefficients of the NPs and persistent bubbles in the individual liquids (compare Fig. $4 \mathrm{c}$ and $\mathrm{d}$ ).

For further evaluation, the Schmidt number $(S c)$ was calculated according to eq. 4 .

$S c=\frac{v}{D}=\frac{P e_{a x}}{R e}$

The $S c$ is defined by the ratio of the kinematic viscosity $v$ of the liquid to the diffusion coefficient $D$ of the NPs or persistent bubbles but can also be derived from the ratio of $P e_{a x}$ to $R e$. The higher the $S c$, the more difficult it becomes for the NPs and persistent bubbles to cross the interface layer. This case is particularly pronounced in ethylene glycol, where the $S c$ of NPs $\left(1.8 \pm 0.2 \cdot 10^{7}\right)$ is 2000 times higher than in water $\left(1.8 \pm 0.4 \cdot 10^{4}\right)$ and even 14,000 times higher than in acetone $\left(1.3 \pm 0.3 \cdot 10^{3}\right)$. For persistent bubbles, the trend is comparable, leading to the highest $S c$ of $5.3 \pm 0.1 \cdot 10^{10}$ in ethylene glycol followed by water $\left(2.5 \pm 1.9 \cdot 10^{7}\right)$ and acetone $(1.2 \pm$ $\left.1.0 \cdot 10^{7}\right)$. Accordingly, the local concentration of NPs and persistent bubbles should be highest near the target surface in ethylene glycol, which is visually confirmed by Fig. 3. This clearly shows that the total quantity of shielding entities (persistent bubbles and NPs) is inadequate to explain ablation shielding alone in liquid flow. However, their confinement in the interface layer seems to rule the LAL ablation rate. In ethylene glycol, this confinement is strongest (Fig. 5d).

For further discussion, the velocity of persistent bubbles formed during ns-LAL of Au in ethylene glycol was calculated, as illustrated in Fig. 6 a.

The procedure was performed for two different types of bubbles: i) bubbles directly located at the target surface, and ii) bubbles located further away $(\leq 0.3 \mathrm{~mm})$ from the target surface. Two observations can be made: Firstly, persistent bubbles directly located at the target surface move slower than those located further away, consistent with the expectations 
a)

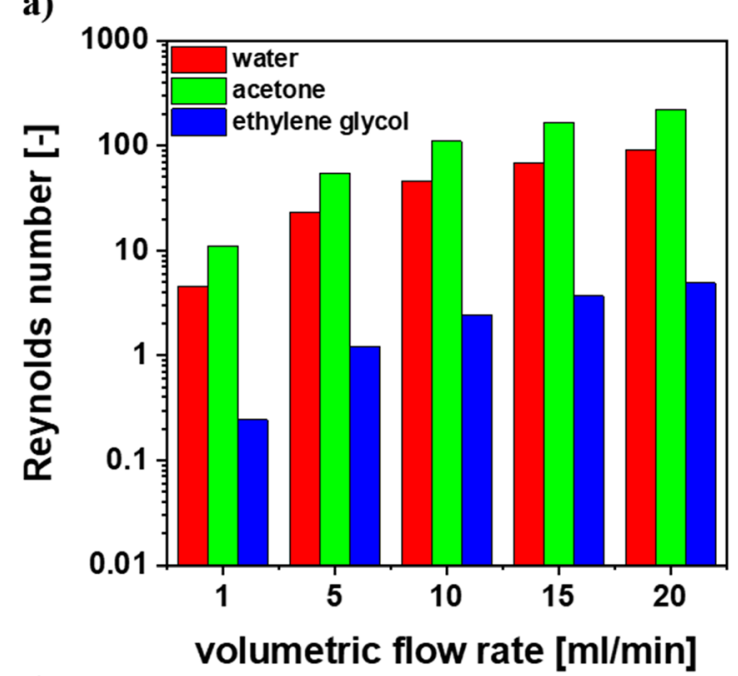

c)

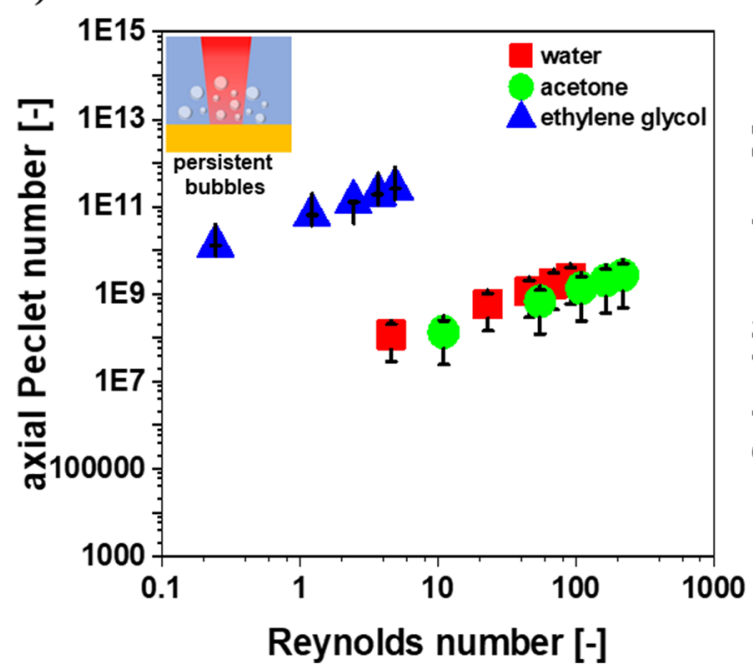

Fig. 5 a Calculation of the Reynolds number depending on the type of liquid and volumetric flow rate. b,c Axial Peclet number as a function of the Reynolds number calculated for NPs and persistent bubbles produced

from the flow velocity gradient. Secondly, the bubble velocity increases with increasing flow velocity. The increase in bubble velocity is not unexpected since the interface layer's thickness decreases with increasing flow velocity. Hence, higher flow velocities are already achieved at lower distances to the target surface [88]. Unfortunately, such calculations cannot be provided for persistent bubbles formed in water and acetone since the camera's time resolution was too low to capture the bubble movement in these liquids. However, if the theoretically expected flow velocity profile is taken into account, which can be approximated by a quadratic function [76], one would expect an increase in the flow velocity near the target surface with decreasing liquid viscosity. The increasing flow velocities not only promote the removal of the bubble from the target surface in low viscosity liquids but also lead to the highest bubble velocities in acetone, followed by water. b)

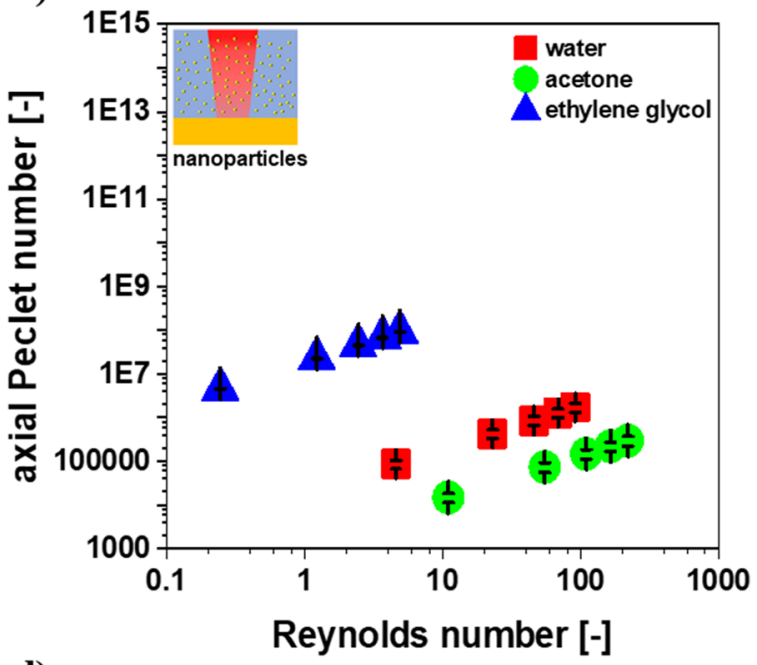

d)

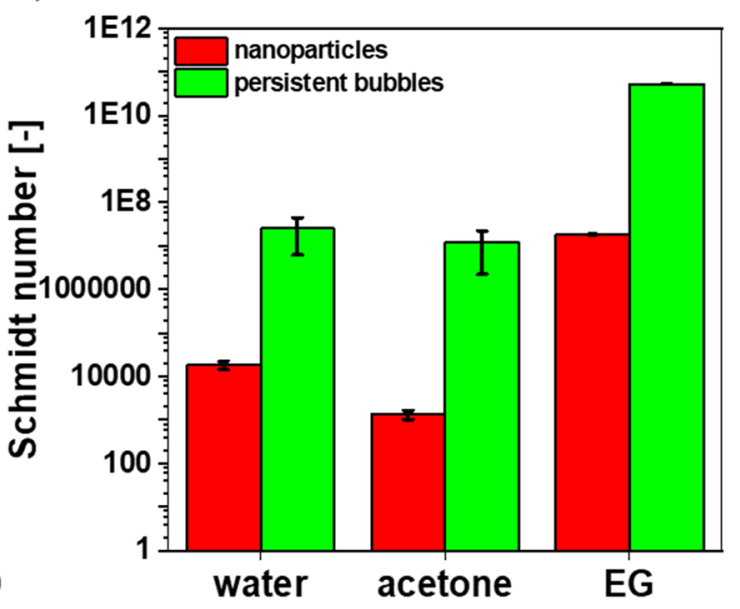

during ns-LAL of $\mathrm{Au}$ in water, acetone, and ethylene glycol. A liquid temperature of $298 \mathrm{~K}$ was considered for the calculations. d Corresponding Schmidt numbers

Note that the persistent bubbles may partially adhere to the target surface before they are removed by the liquid flow [68]. Therefore, the simplified model used to describe the forces determining the detachment of persistent bubbles in a stationary liquid [68], needs to be extended. For this purpose, the additional forces acting on the bubbles in a flowing liquid in parallel and perpendicular direction to the target surface were considered. The most important forces are displayed in Fig. $6 \mathrm{~b}$ and can be summarized as follows:

i) the surface tension force $F_{s}$, which is caused by the liquid's attraction to the target surface, acting around the perimeter of the bubble base $[89,90]$.

ii) the buoyancy force $F_{B}$ encompassing both gravity $\left(F_{g}\right)$ and Archimedes forces [90-92]. 
Fig. 6 a Bubble velocity near and $3 \mathrm{~mm}$ above the target surface as a function of the flow velocity calculated for persistent bubbles produced during ns-LAL of Au in ethylene glycol. b Schematic of the forces acting on persistent bubbles near the bulk surface during liquid flow conditions a)

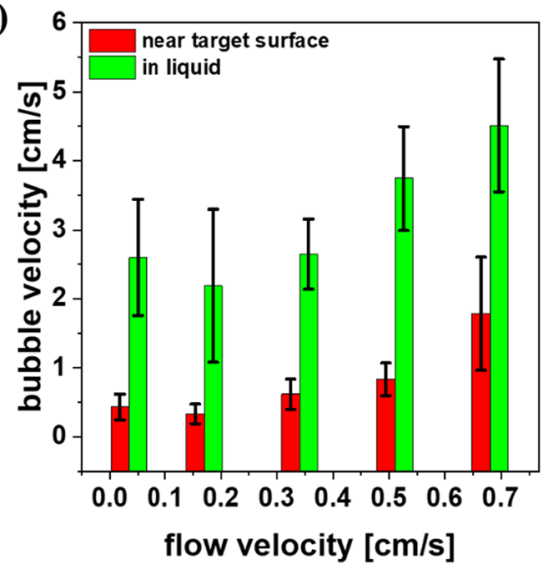

b)

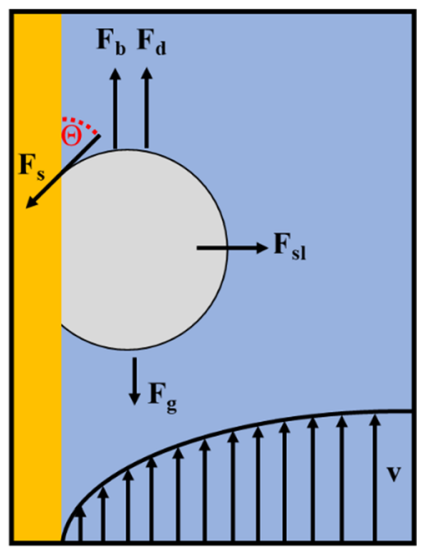

iii) the shear lift force $F_{s l}$, which lifts the bubble in the perpendicular direction to the target surface depending on the liquid flow velocity profile near the target surface [91-93].

iv) the drag force $F_{d}$, which acts opposite to the bubbles' movement relative to the liquid's flow velocity [94].

These forces can be summarized in the form of a force balance (eq. 5) defining the bubbles' detachment from the target surface and their movement in the liquid.

$F_{b}+F_{s l}+F_{d}-F_{s}-F_{g}=0$

When the forces that hold the bubble at the target surface (negative sign) are overcompensated by the forces that pull the bubble away from the target surface (positive sign), the bubble detaches and is carried away with the flow. In this context, the surface tension force is the most important force that prevents the bubble from detachment. Its value increases with increasing bubble contact diameter and further depends on the bubble wettability. In water $\left(\sigma_{1}=0.073 \mathrm{~N} / \mathrm{m}\right.$ at $293 \mathrm{~K}$ [464]), the hydrophobic [422] gold target surface is more aerophilic than in ethylene glycol $\left(\sigma_{1}=0.048 \mathrm{~N} / \mathrm{m}\right.$ at $293 \mathrm{~K}$ [464] $)$ and acetone $\left(\sigma_{1}=0.023 \mathrm{~N} / \mathrm{m}\right.$ at $293 \mathrm{~K}$ [464] $)$ due to the higher surface tension of the corresponding liquids [133]. Consequently, the bubble wettability and capturing ability on the target surface are the highest in water followed by ethylene glycol and acetone.

When the bubbles reach a critical size and the flow velocity is high enough, the drag force and buoyancy force overcompensate the surface tension force, and the bubbles detach. Note that the drag force's direction is reversed after the bubble's detachment since then the bubble velocity is higher than the flow velocity (Fig. 6a). Interestingly, most bubbles, particularly in ethylene glycol, are located near the target surface, indicating that the liquid flow velocity is too low to lift the bubbles perpendicular to the target surface. As a result, the bubbles accumulate at the target surface and slowly slide along it.

\section{Bubble size characteristics and shielding capacity}

In the next step, the bubble size characteristics are discussed in more detail. Fig. 7a-c shows exemplary picture series of the formation of persistent bubbles in all three liquids taken at volumetric flow rates of 1,10 , and $20 \mathrm{ml} / \mathrm{min}$.

The pictures were taken after ablation times of ten seconds to ensure steady-state conditions. Note that for better visualization of the recordings, uniform mean grey values were used for all pictures. As evident in the picture series, the persistent bubbles' average size varies from liquid to liquid. At a volumetric flow rate of $1 \mathrm{ml} / \mathrm{min}$, the average bubble diameter (Fig. 7d) is the smallest in water $(28 \pm 20 \mu \mathrm{m})$. In contrast, larger bubbles were found in acetone $(52 \pm 58 \mu \mathrm{m})$ and ethylene glycol $(57 \pm$ $43 \mu \mathrm{m})$. Consequently, the cross-sectional areas and volumes of persistent bubbles formed in acetone and ethylene glycol are also larger than in water (Fig. 7e and f).

The persistent bubbles' size seems to be unaffected by the applied volumetric flow rate in water and acetone. In contrast, the bubble size in ethylene glycol increases significantly at the transition from 5 to $10 \mathrm{ml} / \mathrm{min}$. A further increase in the volumetric flow rate does not affect the bubble size any further. This behavior can be attributed to a combined process of bubble detachment and the formation of new persistent bubbles. At the transition point, new persistent bubbles are generated faster than they can be removed. Consequently, the probability of interaction and coalescence between them increases, in particular at high $S c$ numbers. In low-viscosity liquids, persistent bubbles are removed faster than new ones are produced so that the final bubble size is less affected by coalescence effects.

In the following, the cross-sectional area for all persistent bubbles was calculated using the procedure described in [68]. The results are displayed in Fig. 8a.

With an average value of $0.15 \mathrm{~mm}^{2}$, the cross-sectional area of the bubbles in water remains almost constant over the entire 
a)

b)
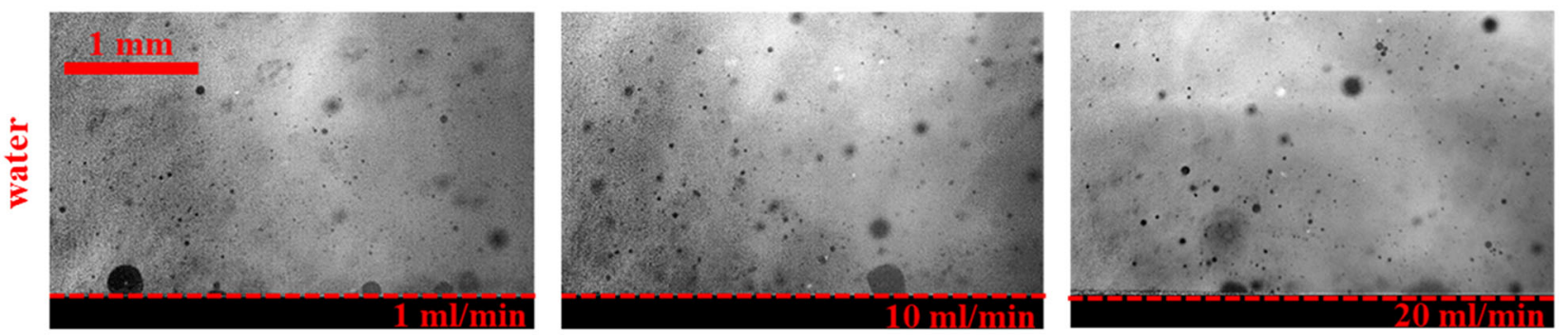

c)
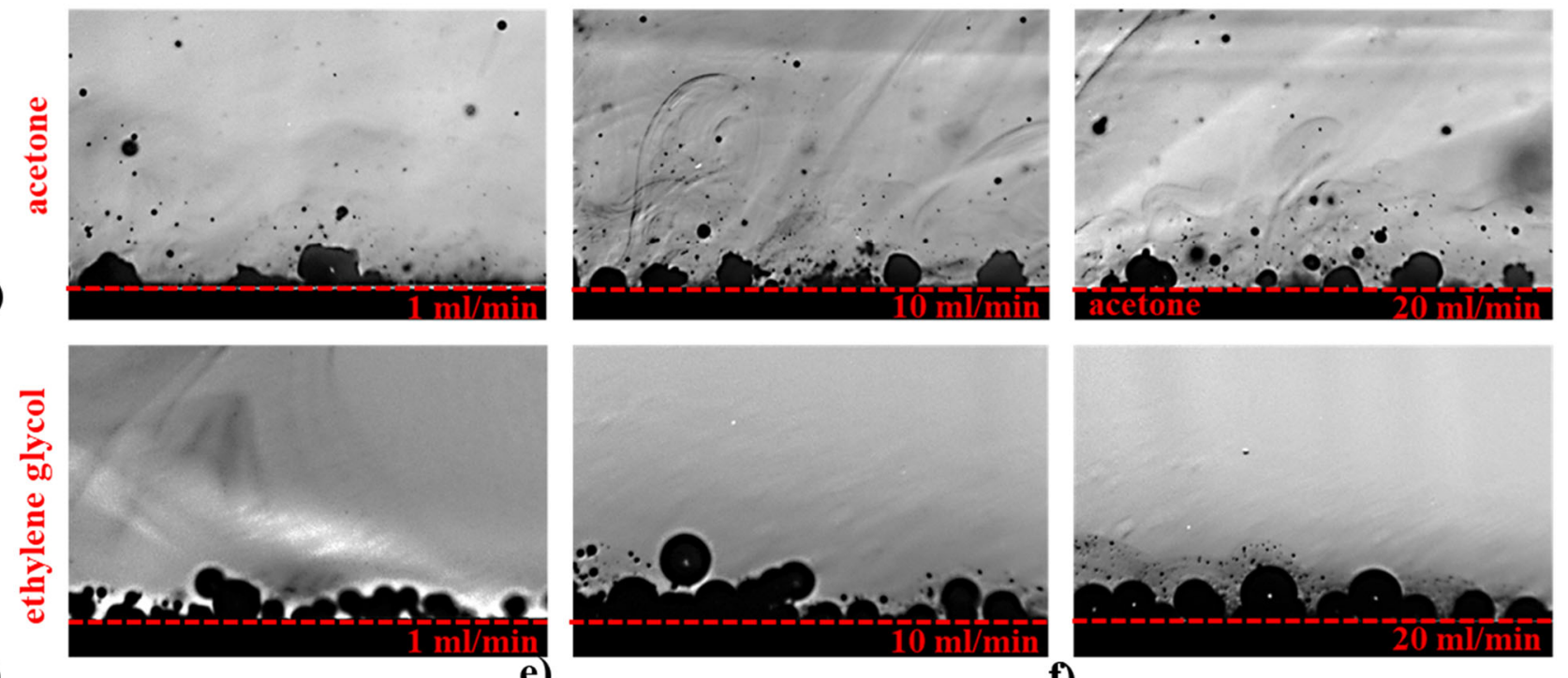

d)

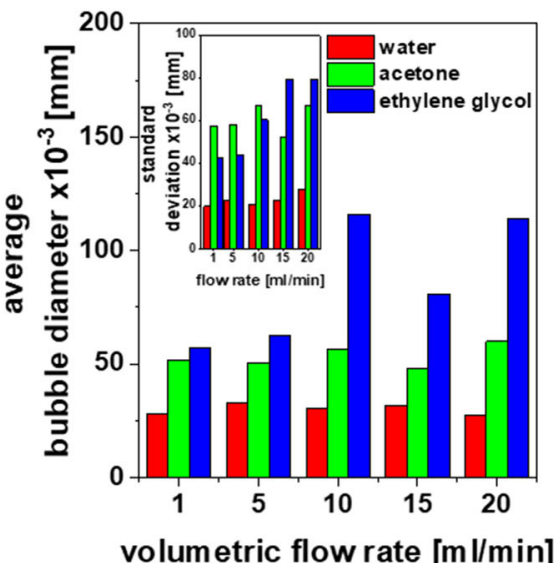

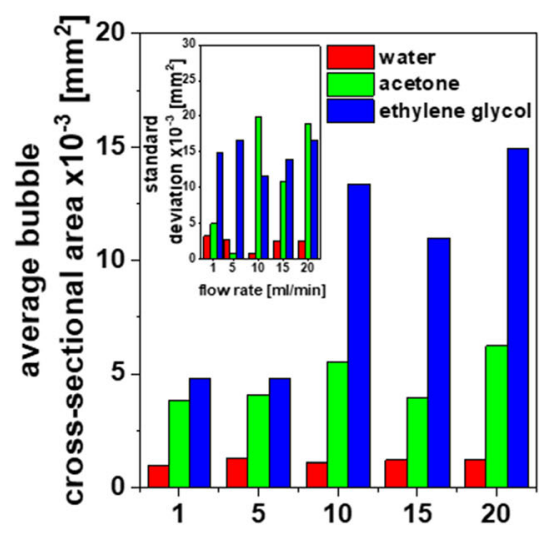

volumetric flow rate $[\mathrm{m} / / \mathrm{min}]$ f)

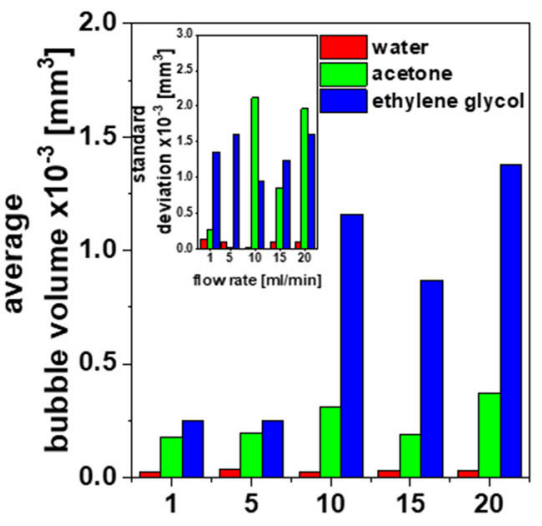

volumetric flow rate $[\mathrm{m} / / \mathrm{min}]$
Fig. 7 a-c Exemplary picture series taken after $10 \mathrm{~s}$ demonstrating the distribution of persistent bubbles in water, acetone, and ethylene glycol at volumetric flow rates of 1,10 , and $20 \mathrm{ml} / \mathrm{min}$. d-f Corresponding average

volumetric flow rate regime. In acetone, the bubbles' crosssectional area increases to $0.34 \pm 0.06 \mathrm{~mm}^{2}$, while in ethylene glycol, a value of $0.34 \pm 0.06 \mathrm{~mm}^{2}$ was found at a maximum volumetric flow rate of $20 \mathrm{ml} / \mathrm{min}$. Consequently, $5 \%$ of the liquid-cross section is shielded by persistent bubbles produced during ablation in water. In contrast, this value increases to $8 \%$ in acetone and $10 \%$ in ethylene glycol.

Since most persistent bubbles are located near the target surface, the determination of the bubble-induced shielding effect, considering only its average in the total liquid cross-section, is bubble diameter, cross-sectional area, and volume depending on the volumetric flow rate

subject to great inaccuracy. Therefore, the fraction of bubbles occupying the target surface was calculated. By measuring the gray value along a defined area above the target surface, the target surface occupation profile was determined (Fig. 8b). A value of $0 \%$ corresponds to the blank target surface without persistent bubbles, while higher values indicate that persistent bubbles are present on the target surface. This way, it is possible to estimate the percentage of the target area occupied with bubbles (Fig. 8c). The target surface occupation is lowest in water $(10-20 \%)$ and increases in acetone $(40-50 \%)$ and ethylene 
a)

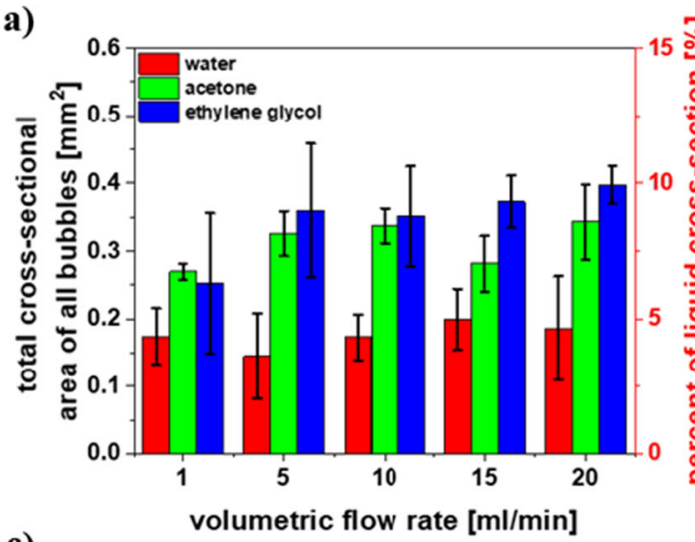

c)

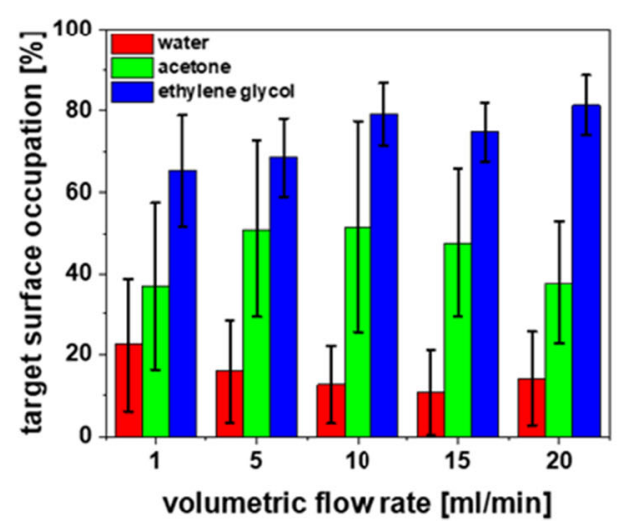

Fig. 8 a Total cross-sectional area of all persistent bubbles produced during ns-LAL of $\mathrm{Au}$ in water, acetone, and ethylene glycol as a function of the volumetric flow rate. The percent of liquid cross-section is plotted on the right y-axis. b Exemplary target occupancy profile along the target surface for persistent bubbles produced in acetone at a volumetric flow

glycol $(80 \%)$. As a result, more target surface is available for ablation in water than in acetone and ethylene glycol so that the highest NP production rate would be expected in water.

The camera setup's temporal and lateral resolution limits made it difficult to visualize and quantify all persistent bubbles. Therefore, the total gas volume formation rate was determined quantitatively by applying the liquid displacement method described in the experimental section and used in previous works [69]. The results obtained after ten minutes of ablation were extrapolated to one hour, as displayed in Fig. $8 \mathrm{~d}$. For all liquids, the gas volume formation rate increases steadily with increasing volumetric flow rate. In water, the gas volume formation rates range from $1.2 \pm 0.1$ to $3.2 \pm$ $0.2 \mathrm{~cm}^{3} / \mathrm{h}$ and increase by a factor of 20 in acetone $\left(19.2 \pm 1.0\right.$ to $\left.62.4 \pm 3.1 \mathrm{~cm}^{3} / \mathrm{h}\right)$ and ethylene glycol $\left(24.0 \pm 1.2\right.$ to $\left.64.0 \pm 3.2 \mathrm{~cm}^{3} / \mathrm{h}\right)$. The same trend can be observed for the molar gas formation rates, calculated by dividing the gas volume formation rates by the molar volume $(22.414 \mathrm{~L} / \mathrm{mol})$, assuming an ideal gas. The molar gas formation rates are lowest in water ranging from 0.05 \pm 0.01 to $0.14 \pm 0.01 \mathrm{mmol} / \mathrm{h}$ and increase in acetone $(0.86 \pm 0.04$ to $2.78 \pm 0.14 \mathrm{mmol} / \mathrm{h})$ and ethylene glycol

\section{b) \\ d)}
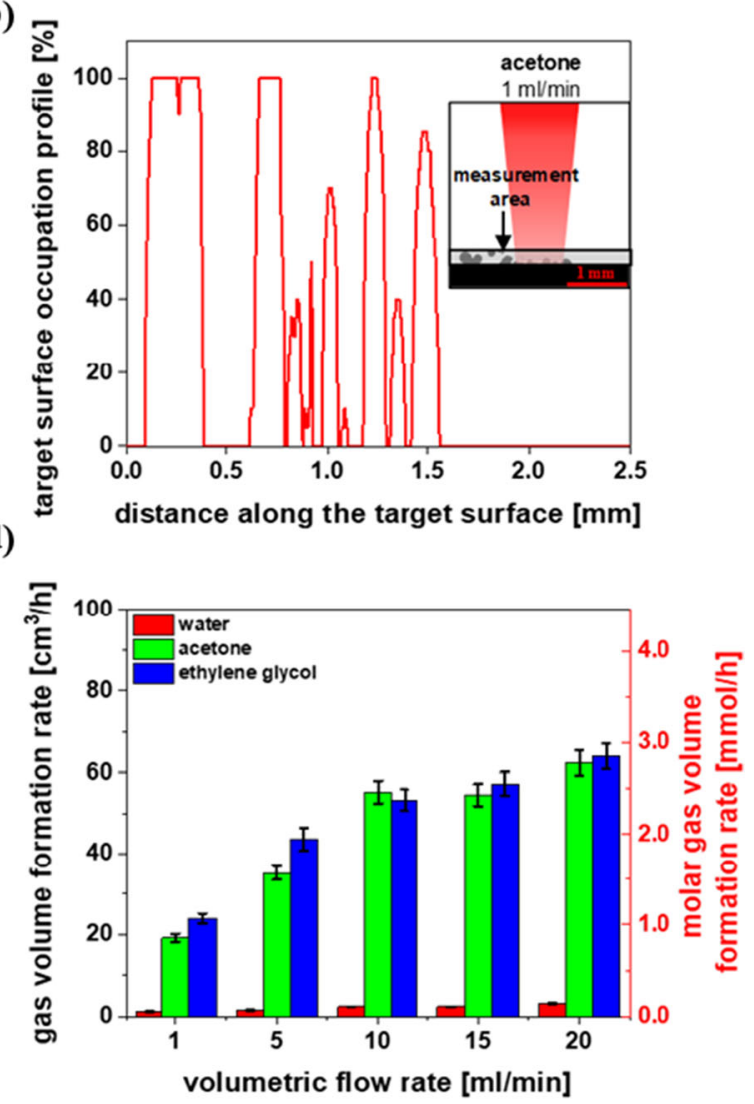

rate of $1 \mathrm{ml} / \mathrm{min}$. $\mathbf{c}$ Percentage of persistent bubbles occupying the target surface in the different liquids as a function of the volumetric flow rate. $\mathbf{d}$ Gas volume formation rates in $\mathrm{cm}^{3}$ and $\mathrm{mmol}$ (assuming an ideal gas with $22.4 \mathrm{l} / \mathrm{mol}$ ) per hour as a function of the volumetric flow rate

$(1.07 \pm 0.05$ to $2.85 \pm 0.14 \mathrm{mmol} / \mathrm{h})$. In summary, the ablation in acetone and ethylene glycol leads to the formation of significantly larger amounts of gases than in water.

\section{Correlation of the mass ablation rate with the shielding effects induced by the persistent bubbles and nanoparticles}

At this point, the question arises how the mass ablation rate is influenced by the formation of persistent bubbles and NPs depending on the liquids and volumetric flow rates. For this purpose, the NP production rate was determined, summarized for each liquid and volumetric flow rate in Fig. 9a.

The results demonstrate the highest NP production rates for ns-LAL of Au in water, followed by ethylene glycol and acetone. Moreover, the NP production rate increases with increasing volumetric flow rate. This way, NP production rate ranges from $36 \pm 2$ to $74 \pm 4 \mathrm{mg} / \mathrm{h}$ in water, whereas in acetone, it decreases by about $10 \%(30 \pm 2$ to $61 \pm 3 \mathrm{mg} / \mathrm{h})$. The NP production rates obtained in ethylene glycol range from $33 \pm 2$ to $71 \pm 4 \mathrm{mg} / \mathrm{h}$, laying between water and acetone. By dividing the NP production rate by the laser power, the 
specific NP production rate was calculated, resulting in values of $7.6 \pm 0.4$ to $15.7 \pm 0.8 \mathrm{mg} /(\mathrm{W} \cdot \mathrm{h})$ in water, $6.3 \pm 0.42$ to $12.9 \pm 0.6 \mathrm{mg} /(\mathrm{W} \cdot \mathrm{h})$ in acetone, and $7.0 \pm 0.4$ to $15.0 \pm$ $0.8 \mathrm{mg} /(\mathrm{W} \cdot \mathrm{h})$ in ethylene glycol. For ns-LAL of Au in water, Kohsakowski et al. found a specific NP production rate of $18 \mathrm{mg} /(\mathrm{W} \cdot \mathrm{h})$ [95], which is in good agreement with the values found in this study. However, note that they used 25 times more laser power, while the NP mass concentration was three times higher than in the present study. Therefore, their productivity data may not represent the upper limit of what would be possible if higher dilution rates (resulting in lower NP shielding effects) were used.

Different productivity trends were reported for laser ablation in acetone in literature. While Bärsch et al. found higher ablation efficiencies in acetone than in water [96], the opposite trend was observed in other studies [29, 97, 98]. In contrast, low (specific) NP production rates were typically obtained for ns-LAL in ethylene glycol, explained by viscosity effects [58, 68]. However, most of these studies were performed in (typically horizontally orientated targets and) batch chambers without liquid flow. Therefore, shielding effects induced by persistent bubbles and NPs could have affected the ablation results. It should be noted that shielding effects cannot be completely avoided even when using a liquid flow and lowviscous liquids, as the ablation profile analysis in Fig. 10 illustrates.

The ablation pattern analysis demonstrates that the target front (near the chamber inlet) is ablated more efficiently than the target end. The differences in local ablation efficiencies can be explained by concentration gradients built up by NPs and persistent bubbles along the target surface in the liquid flow direction.

For further discussion, the NP production rate was plotted against the NP mass concentration to account for the NPinduced shielding effect (Fig. 9b). The overall trend can be described by an exponential fit leading to the lowest NP production rates at the highest NP mass concentrations. The higher the volumetric flow rates, the higher the dilution rates. Consequently, the NP mass concentration decreases, and the NP production rate increases. It is worth mentioning that the NP production rate is highest in water, although the NP mass concentration $(62 \pm 3$ to $598 \pm 30 \mathrm{mg} / \mathrm{l})$ is higher than in ethylene glycol $(58 \pm 3$ to $550 \pm 27 \mathrm{mg} / \mathrm{l})$ and acetone $(51 \pm 3$ to $504 \pm 25 \mathrm{mg} / \mathrm{l})$. At first view, this trend is unexpected since one would assume the same NP production rate at the same NP mass concentration. However, two points need to be considered: Firstly, the bubble shielding is the lowest in water (Fig. 8). Secondly, the colloidal system's shielding capacity depends on the size characteristics of the NPs [68]. Information about the NP size and the agglomeration states can be extracted from the colloids' UV-Vis extinction spectra (Fig. 11a).

Generally, the surface plasmon resonance (SPR) of Au NPs results in a strong absorbance band in the visible region around $500-600 \mathrm{~nm}$ [99]. The SPR band is shifted to longer wavelengths when the size of Au NPs increases [99]. Furthermore, agglomeration of Au NPs leads to a redshift of the SPR band accompanied by a broadening of the absorption peak $[100,101]$. Compared to Au NPs formed in water and acetone, for which the SPR band is located around $520 \mathrm{~nm}$, the SPR band of Au NPs produced in ethylene glycol is broader and shifted to longer wavelengths at $570 \mathrm{~nm}$. From this, it can be concluded that Au NPs produced in ethylene glycol are either larger or more agglomerated than in water and acetone.

For further evaluation, the primary particle index (PPI) was calculated (Fig. 11b). The PPI is defined as the ratio of the interband absorption at a wavelength of $380 \mathrm{~nm}$ to the scattering signal of aggregates, agglomerates, and larger particles at a wavelength of $800 \mathrm{~nm}$ [102]. This way, it is possible to a)

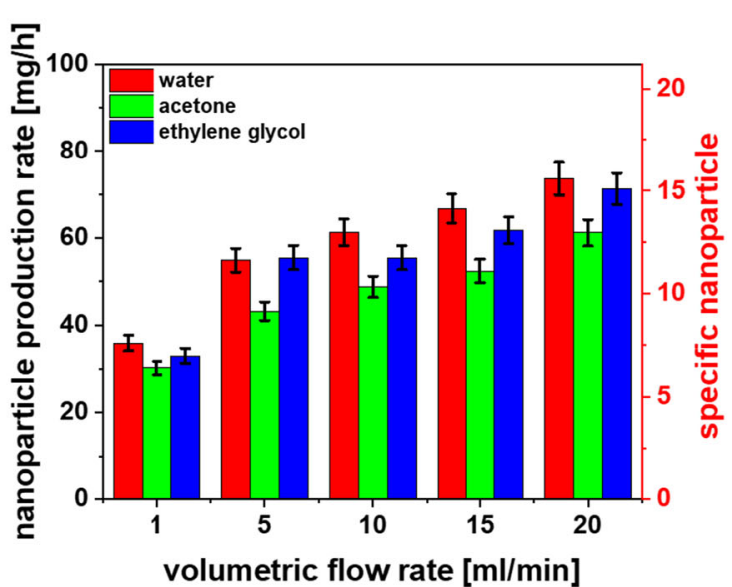

b)

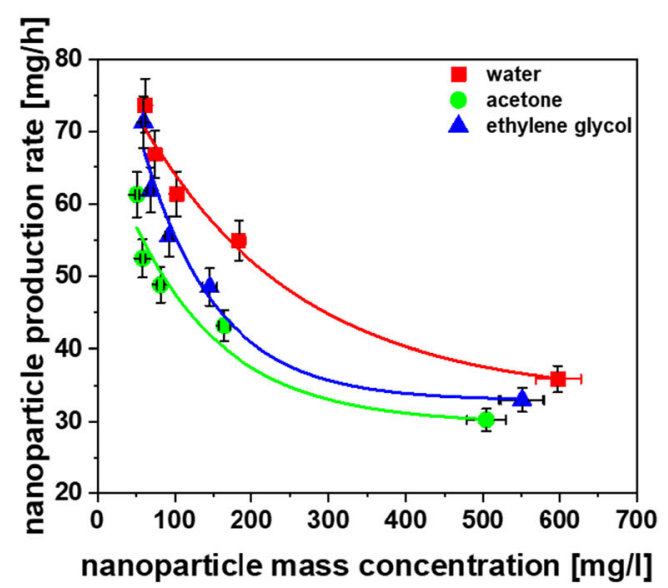

Fig. 9 (a,b) (Specific) NP production rate depending on the volumetric flow rate and NP mass concentration for ns-LAL of Au in water, acetone, and ethylene glycol 
Fig. 10 Confocal 3D microscopy image of the ablation depth profile obtained after ns-LAL of $\mathrm{Au}$ in water at a volumetric flow rate of $10 \mathrm{ml} / \mathrm{min}$

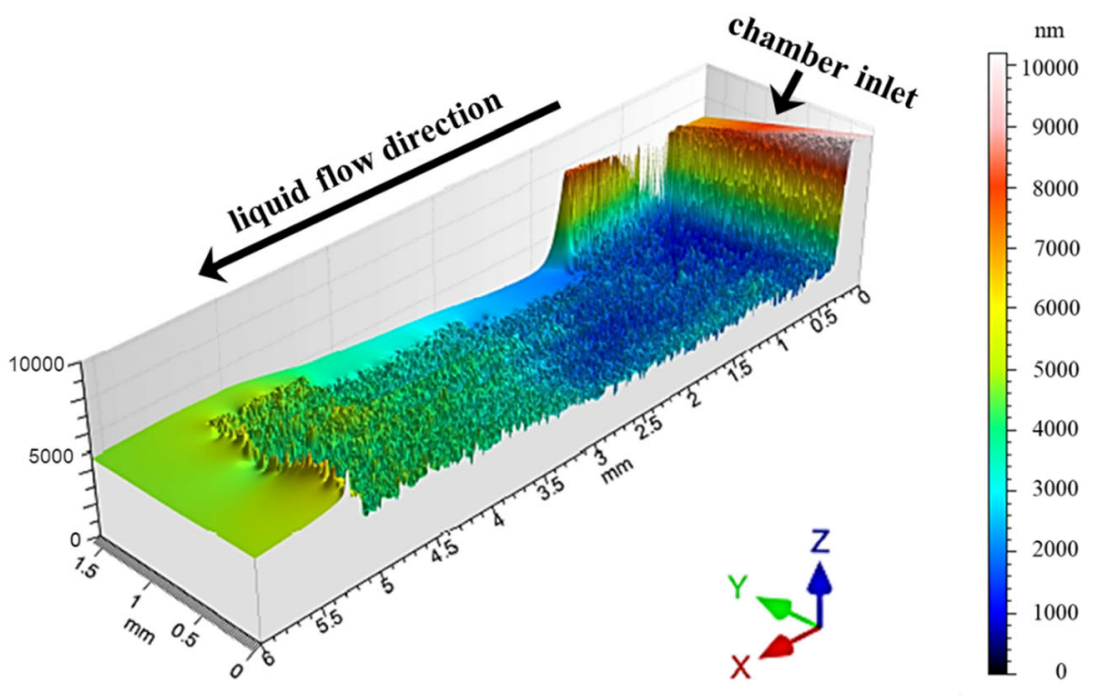

estimate the degree of agglomeration of the Au NPs if imaging techniques such as TEM are included. A PPI of 1 was calculated for Au NPs formed in ethylene glycol, while for Au NPs produced in water and acetone, significantly higher PPIs of 7 and 15 were found. TEM measurements have shown that nsLAL of $\mathrm{Au}$ in water and acetone leads to NPs with primary particle diameters around $10 \mathrm{~nm}[68,103]$, which is in good agreement with the hydrodynamic diameter determined by DLS in the present study (Fig. 11c-e). For ethylene glycol, TEM measurements yielded primary particle diameters of about $10 \mathrm{~nm}$ as well [68], while in this study, hydrodynamic diameters of about $35 \mathrm{~nm}$ were measured by DLS. Combining the particle sizes from TEM and DLS with the PPI, it can be concluded that Au NPs tend to agglomerate in ethylene glycol, whereas they are more monodisperse in acetone and water.

The high agglomeration propensity in ethylene glycol is unexpected from the first point of view since a lower particle mobility should enhance the colloidal particle stability [104]. However, this only applies if the NPs are evenly dispersed in the liquid. As mentioned above, the mixing of NPs in ethylene glycol is less effective than in water and acetone due to the slower flow velocities in the interface layer near the target surface and low NP diffusion coefficients. Consequently, the NPs are more concentrated towards the target surface (as deduced from Figs. $3 \mathrm{c}$ and $7 \mathrm{~d}$ ), which may increase the propensity of the NPs to agglomerate.

Since scattering effects become more pronounced as the colloidal stability decreases [57], the formation of agglomerates may also increase the colloid-induced shielding effect. To verify this assumption, the fraction of the laser fluence shielded by the colloids was measured (see appendix Fig. 14a-c). This procedure allows the calculation of the laser fluence available for target ablation, as shown in Fig. 12. Considering the attenuation of the laser intensity in the liquid and the laser light extinction by the colloid, the effective laser fluence available for target ablation is higher in water and acetone than in ethylene glycol. The effective laser fluence decreases steadily from 24.2 to $17.1 \mathrm{~J} / \mathrm{cm}^{2}$ in acetone and from 23.1 to $11.7 \mathrm{~J} / \mathrm{cm}^{2}$ in water. In contrast, it decreases exponentially from 23.4 to $4.5 \mathrm{~J} / \mathrm{cm}^{2}$ in ethylene glycol, indicating that the contribution of agglomeration to colloid-induced shielding strongly increases with increasing NP mass concentration and liquid viscosity. Overall, up to $81 \%$ of the laser fluence is shielded by the colloids in ethylene glycol, whereas it is $29 \%$ in acetone and $49 \%$ in water.

Summarizing the shielding effects induced by the persistent bubbles and NPs, one would expect the highest mass ablation rates for ns-LAL of $\mathrm{Au}$ in water, followed by acetone and ethylene glycol. Although the expectations for water can be confirmed, the trend for acetone and ethylene glycol is contradictory. Kanitz et al. stated that the ablation process alters at a stage after energy deposition [98]. They found that the ablation efficiency strongly correlates with the light intensity emitted by the plasma formed during the first few nanoseconds after a 35 fs laser pulse. Consequently, the highest ablation efficiencies were achieved in those liquids where the formed plasma had the strongest light intensity (water followed by acetone and toluene; ethylene glycol was not investigated). Choi et al. suggested that solvents with a low specific heat cool the plasma more effectively, affecting the formation of metastable nanomaterials and perhaps also the ablation yield [105]. Taking into account the specific heats of water $(4.18 \mathrm{~J} /(\mathrm{g} \cdot \mathrm{K}))$, acetone $(2.16 \mathrm{~J} /(\mathrm{g} \cdot \mathrm{K}))$, and ethylene glycol $(2.5 \mathrm{~J} /(\mathrm{g} \cdot \mathrm{K}))$ [106], their order would fit the trend in NP production rate. However, before an exact statement can be made about the liquid's influence on the cooling of the plasma, further experiments, and modeling are 
a)

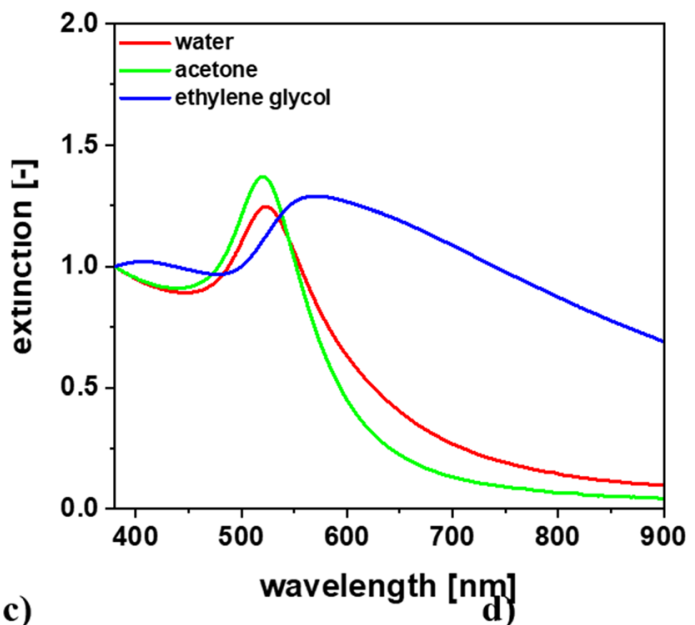

c)
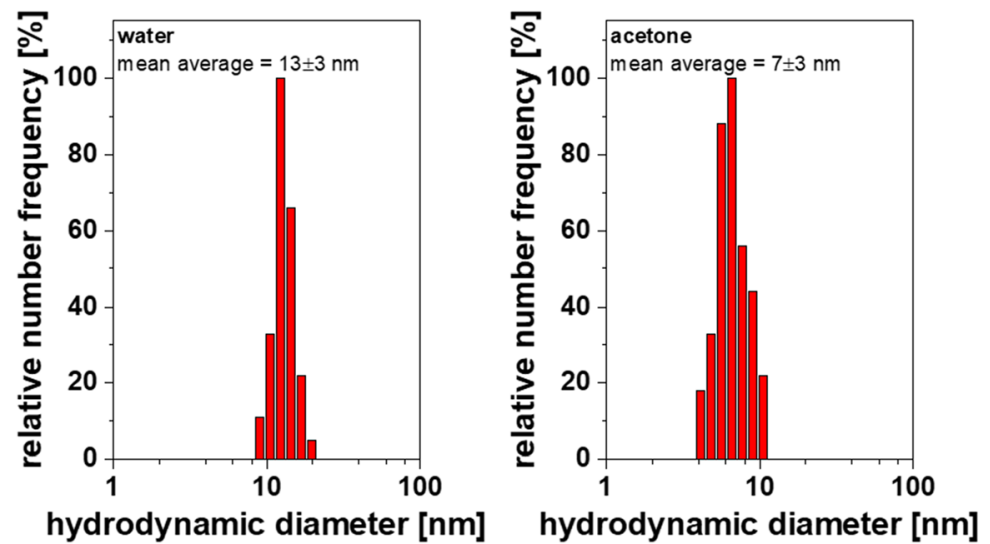

b)

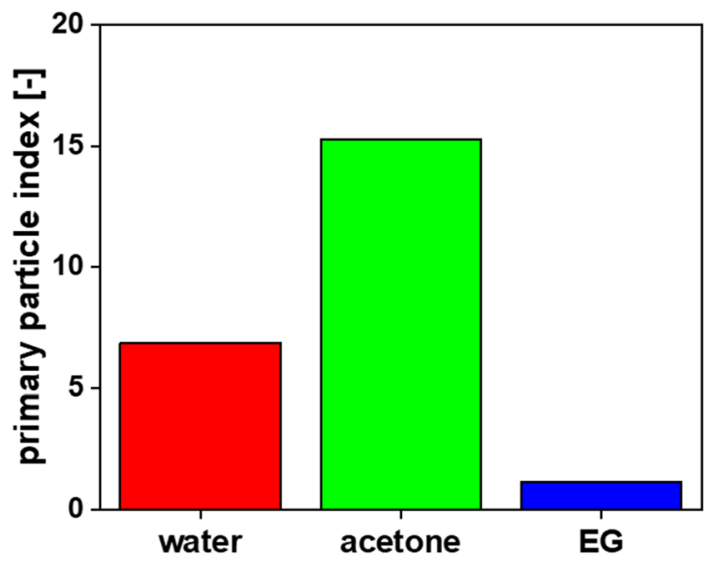

e)

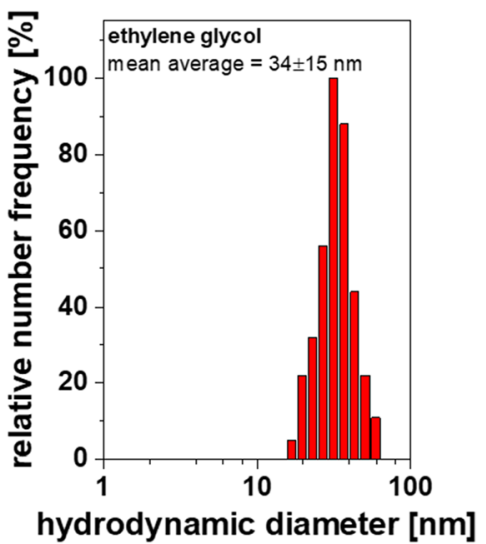

Fig. 11 a Exemplary UV-Vis extinction spectra of colloids produced by ns-LAL of Au in water, acetone, and ethylene glycol (EG) at a volumetric flow rate of $5 \mathrm{ml} / \mathrm{min}$. The UV-Vis spectra are normalized on the interband absorption of Au at $380 \mathrm{~nm}$. b Primary particle index calculated

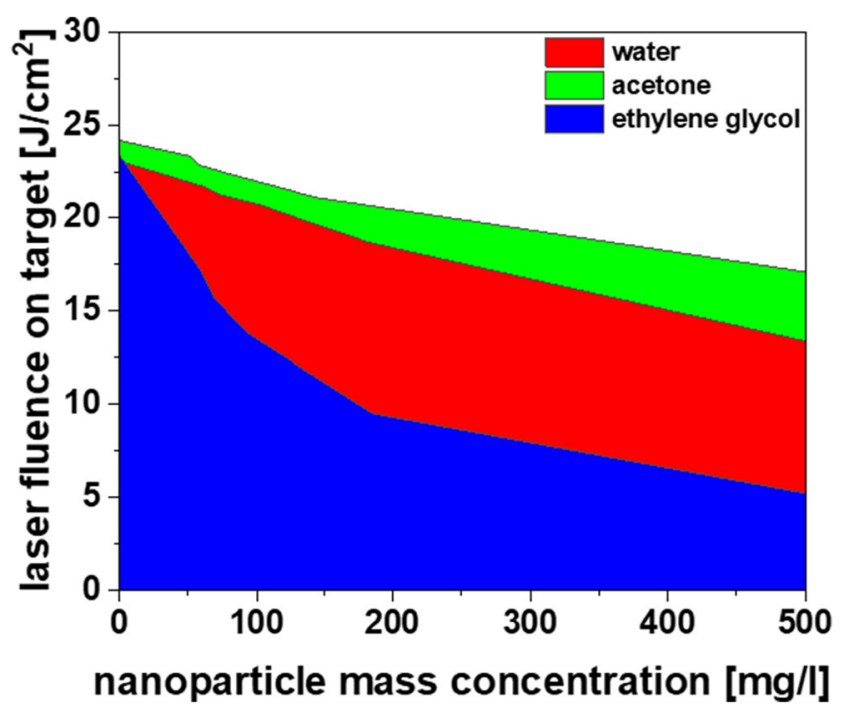

Fig. 12 Effective laser fluence available for target ablation as a function of the NP mass concentration, by measuring the laser power attenuation at these concentrations by $\mathrm{E}_{380 \mathrm{~nm}} / \mathrm{E}_{800 \mathrm{~nm}}$ c-e Number-weighted hydrodynamic diameter of $\mathrm{Au}$ NPs produced by ablation in water, acetone, and ethylene glycol at a volumetric flow rate of $20 \mathrm{ml} / \mathrm{min}$. The size measurements were performed using dynamic light scattering

necessary. Furthermore, the liquid's chemical reactivity during (the early phase) of LAL could be important, as discussed in the next section.

\section{Correlation of the NP-induced shielding effects and the mass ablation rate with the gas formation efficiency}

In the last section of this work, the gas formation pathway is discussed by linking the laser power used for ablation, the NPinduced shielding effects, and the gas formation and mass ablation rates to each other. For this purpose, the total specific gas volume was first calculated by dividing the gas volume formation rate by the NP production rate and the total applied laser power, as shown in Fig. 13a.

The results indicate that the total specific gas volume is slightly higher at low nanoparticle mass concentrations below $200 \mathrm{mg} / \mathrm{l}$. In water, total specific gas volumes of $0.01 \mathrm{~cm}^{3} /$ $(\mathrm{mg} \cdot \mathrm{W})$ were obtained, while in acetone and ethylene glycol, 
a)

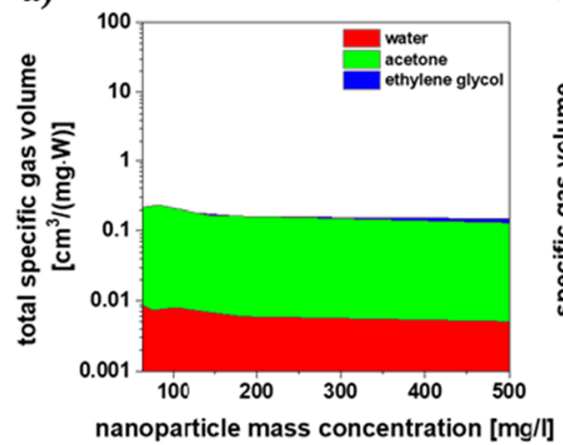

b)

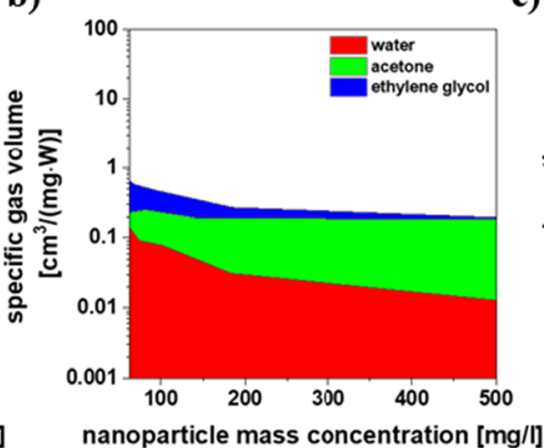

c)

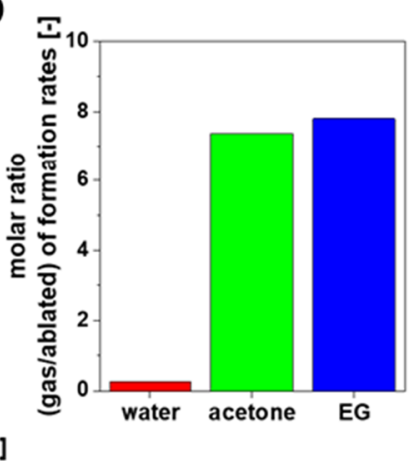

Fig. 13 Specific gas volume formed during ns-LAL of $\mathrm{Au}$ in water, acetone, and ethylene glycol (EG) depending on the NP mass concentration: a normalized to the total applied laser power and $\mathbf{b}$ normalized to the laser power available for bulk ablation. $\mathbf{c}$ Molar ratio of the amount of formed gas to the amount of ablated mol at a nanoparticle mass concentration of $200 \mathrm{mg} / \mathrm{l}$.

above a specific NP mass concentration, the gas formation process is dominated by post-irradiation of NPs and the formation of nanobubbles while the target-ablation-related specific gas volume remains rather constant [59]. Consequently, gas formation cross-effects induced by post-irradiation of NPs are also dominant under liquid flow conditions when high NP mass concentrations $>200 \mathrm{mg} / \mathrm{l}$ are reached.

The specific gas volumes depend not only on the NP mass concentration but also on the type of liquid. To further emphasize this dependence, the molar gas volume formation rates were correlated with the molar NP production rate, as shown in Fig. 13c, exemplarily for a NP mass concentration of $200 \mathrm{mg} / \mathrm{l}$. It is evident that the gas formation process is 30 times more efficient in acetone and ethylene glycol than water. In a first approach, the differences in the gas formation efficiencies can be explained by considering the molecular bonds in the vapor phase, which are weaker for acetone and ethylene glycol than water. The decomposition of acetone proceeds by a unimolecular reaction and leads to methane and acetyl radicals, which recombine and decompose further to gas products like molecular hydrogen, methane, ethane, or carbon monoxide and dioxide [107-109]. The most important step is breaking the $\mathrm{C}-\mathrm{C}$ bond $(3.6 \mathrm{eV})$, which is significantly weaker than the $\mathrm{O}-\mathrm{H}$ bond in water vapor $(4.8 \mathrm{eV})[110]$. Ethylene glycol consistent with our previous results, where it was shown that

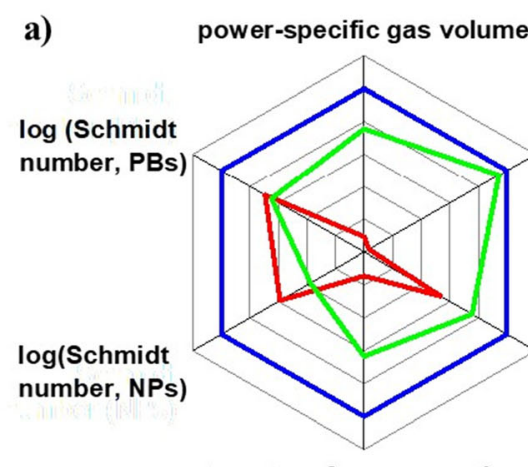

ablation-related gas formation efficiency

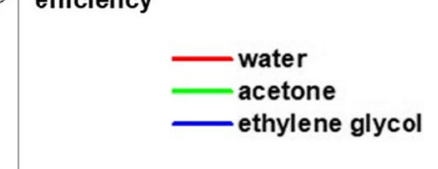

total bubble cross-sectional area b)

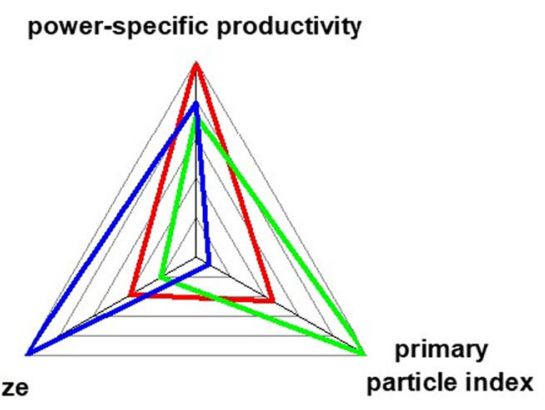

target surface occupation

Fig. 14 Radar chart summarizing determinants (i.e., shielding effects) (a) and read-outs (b) during ns-LAL of Au in water, acetone, and ethylene glycol. The logarithms of the Schmidt numbers for NPs and persistent bubbles (PBs) are plotted for better visibility in the graph 
behaves similarly, supported by the gas formation efficiencies, which are in the same order of magnitude as acetone.

The proposed decomposition pathways are thermal, electron-, or photon-induced reactions triggered by the liquid's interaction with the laser-induced plasma [111]. However, chemical reactions between the target material and the liquid molecules may also be important for the decomposition of the liquid $[69,112]$. For ns-ablation of Au in ethylene glycol, the formation of persistent bubbles, consisting of molecular hydrogen and carbon monoxide as main decomposition products besides smaller amounts of carbon dioxide, methane, acetylene, ethylene, and ethane was confirmed by gas chromatographic measurements [68]. Evangelista et al. also reported the formation of these gas products when heating ethylene glycol in a metal tube to $\sim 1400 \mathrm{~K}$. They suggested that ethylene glycol is catalytically decomposed when the metal tube is coated with a catalytic material such as platinum [113]. The decomposition of ethylene glycol (and acetone) during nsLAL of Au may also have been catalyzed. Such reaction pathways should be further investigated in future experiments by varying the target material and liquid type.

\section{Conclusion}

Commonly, batch conditions are used for lab-scale LAL processing. However, depending on the ablation time and the liquid's transport properties, shielding effects induced by NPs and persistent bubbles increase steadily over time, leading to cross-effects that require their disentanglement in a systematic study. By performing ns-LAL of Au in liquids (water, acetone, and ethylene glycol) of different viscosity and diffusivity and applying a liquid flow above the target surface, it was shown that the complexity of the timedependent shielding effects can be significantly reduced, resulting in a steady-state with constant individual contributions after 0.5 to $2 \mathrm{~s}$. The liquid's ns-LAL key determinants (i.e., shielding effects) and important synthesis read-outs characterized in this study are summarized in Fig. 14.

In Fig. 14a it is evident that all discussed shielding effects are more pronounced for ns-LAL in ethylene glycol where shielding effects strongly depend on the interface layer that forms along the target surface under liquid flow conditions, as indicated by the Schmidt number. By calculating dimensionless numbers (i.e., Reynolds, axial Peclet, and Schmidt number), it was shown that the flow profile is fully laminar (as usual during LAL in liquid flow) and that the viscosity of the liquid controls the accumulation of both NPs and persistent bubbles within an interface layer.

Linked with the highest gas volume formation rates of up to $60 \mathrm{~cm}^{3} / \mathrm{h}$, it was demonstrated that the bubble population concentrates near the target surface in ethylene glycol, shielding up to $80 \%$ of the target surface. For ns-ablation in water, the gas volume formation rates are 20 times lower. Accompanied by a lower diffusion-limitation, bubbles shield only $15-20 \%$ of the target surface. Acetone represents a border case. Here, the gas volume formation rates are comparable to ethylene glycol, but the diffusion-limitation is the lowest. Consequently, the bubble shielding (40-50\%) lies between water and ethylene glycol (Fig. 14a).

Due to the low diffusivity in ethylene glycol, it is also more difficult for the NPs to leave the interface layer. Hence, high NP concentration gradients are built up close to the target surface, promoting the agglomeration of the NPs which is also showcased in Fig. 14b where LAL in ethylene glycol leads to the highest average hydrodynamic particle size. Linked with the stability of the NPs, the formation of agglomerates, and the high colloid-induced shielding, the effective laser fluence available for bulk ablation decreases by $81 \%$ for ethylene glycol, compared to $50 \%$ in water and $30 \%$ in acetone, where lower agglomeration degrees were observed. Hence, within the radar chart shown in Fig. 14a it is recommended to choose a liquid with determinants closer to the center. Accordingly, low viscosity liquids with low gas formation rates are recommended in combination with high flow rates to achieve maximum production rate with a high primary particle index and small average nanoparticle size (Fig. 14).

Nevertheless, the clear solvent-molecular reason for the NP production rate differences within the individual liquids summarized in Fig. 14b remains unclear. It was shown that during ns-LAL of Au in acetone and ethylene glycol, 30 times more gas is produced per ablated amount of substance, indicating the importance of chemical reactions for the ablation yield during the early phase of LAL. Analyzing the plasma characteristics and performing downstream gas chromatography analysis could help clarify the underlying mechanism.

Supplementary Information The online version contains supplementary material available at https://doi.org/10.1007/s41981-021-00144-7.

Acknowledgements The authors gratefully acknowledge funding from the Deutsche Forschungsgemeinschaft (DFG, German Research Foundation) within the projects GO 2566/8-1 (Project ID 440395856) and GO 2566/10-1 (Project ID 445127149).

Funding Open Access funding enabled and organized by Projekt DEAL.

Open Access This article is licensed under a Creative Commons Attribution 4.0 International License, which permits use, sharing, adaptation, distribution and reproduction in any medium or format, as long as you give appropriate credit to the original author(s) and the source, provide a link to the Creative Commons licence, and indicate if changes were made. The images or other third party material in this article are included in the article's Creative Commons licence, unless indicated otherwise in a credit line to the material. If material is not included in the article's Creative Commons licence and your intended use is not permitted by statutory regulation or exceeds the permitted use, you will need to obtain permission directly from the copyright holder. To view a copy of this licence, visit http://creativecommons.org/licenses/by/4.0/. 


\section{References}

1. Dreaden EC, Alkilany AM, Huang X, Murphy CJ, El-Sayed MA (2012) The golden age: gold nanoparticles for biomedicine. Chem Soc Rev 41:2740-2779

2. Idris NM, Gnanasammandhan MK, Zhang J, Ho PC, Mahendran $\mathrm{R}$, Zhang Y (2012) In vivo photodynamic therapy using upconversion nanoparticles as remote-controlled nanotransducers. Nat Med 18:1580

3. Zhu H, Chen X, Jin LM, Wang QJ, Wang F, Yu SF (2013) Amplified spontaneous emission and lasing from lanthanidedoped up-conversion nanocrystals. ACS Nano 7:11420-11426

4. Lu Y, Zhao J, Zhang R, Liu Y, Liu D, Goldys EM, Yang X, Xi P, Sunna A, Lu J (2014) Tunable lifetime multiplexing using luminescent nanocrystals. Nat Photonics 8:32-36

5. Tsunoyama H, Sakurai H, Ichikuni N, Negishi Y, Tsukuda T (2004) Colloidal gold nanoparticles as catalyst for carbon-carbon bond formation: application to aerobic homocoupling of phenylboronic acid in water. Langmuir 20:11293-11296

6. Corma A, Garcia H (2008) Supported gold nanoparticles as catalysts for organic reactions. Chem Soc Rev 37:2096-2126

7. Riche CT, Roberts EJ, Gupta M, Brutchey RL, Malmstadt N (2016) Flow invariant droplet formation for stable parallel microreactors. Nat Commun 7:10780

8. Zhang J, Chen G, Chaker M, Rosei F, Ma D (2013) Gold nanoparticle decorated ceria nanotubes with significantly high catalytic activity for the reduction of nitrophenol and mechanism study. Appl Catal B Environ 132:107-115

9. Kruis FE, Fissan H, Peled A (1998) Synthesis of nanoparticles in the gas phase for electronic, optical and magnetic applications-a review. J Aerosol Sci 29:511-535

10. Swihart MT (2003) Vapor-phase synthesis of nanoparticles. Curr Opin Colloid Interface Sci 8:127-133

11. Kluchova K, Zboril R, Tucek J, Pecova M, Zajoncova L, Safarik I, Mashlan M, Markova I, Jancik D, Sebela M (2009) Superparamagnetic maghemite nanoparticles from solid-state synthesis-their functionalization towards peroral MRI contrast agent and magnetic carrier for trypsin immobilization. Biomaterials 30:2855-2863

12. Cui W, Cheng N, Liu Q, Ge C, Asiri AM, Sun X (2014) $\mathrm{Mo}_{2} \mathrm{C}$ nanoparticles decorated graphitic carbon sheets: biopolymerderived solid-state synthesis and application as an efficient electrocatalyst for hydrogen generation. ACS Catal 4:2658-2661

13. Polte J (2015) Fundamental growth principles of colloidal metal nanoparticles-a new perspective. CrystEngComm 17:6809-6830

14. Kickelbick G (2003) Concepts for the incorporation of inorganic building blocks into organic polymers on a nanoscale. Prog Polym Sci 28:83-114

15. Zhang D, Gökce B (2017) Perspective of laser-prototyping nanoparticle-polymer composites. Appl Surf Sci 392:991-1003

16. Manias E, Touny A, Wu L, Strawhecker K, Lu B, Chung T (2001) Polypropylene/montmorillonite nanocomposites. Review of the synthetic routes and materials properties. Chem Materials 13: 3516-3523

17. Moon RJ, Martini A, Nairn J, Simonsen J, Youngblood J (2011) Cellulose nanomaterials review: structure, properties and nanocomposites. Chem Soc Rev 40:3941-3994

18. Pickard R, Lam T, MacLennan G, Starr K, Kilonzo M, McPherson G, Gillies K, McDonald A, Walton K, Buckley B (2012) Antimicrobial catheters for reduction of symptomatic urinary tract infection in adults requiring short-term catheterisation in hospital: a multicentre randomised controlled trial. Lancet 380: 1927-1935

19. Johnson JR, Kuskowski MA, Wilt TJ (2006) Systematic review: antimicrobial urinary catheters to prevent catheter-associated urinary tract infection in hospitalized patients. Ann Intern Med 144:116-126

20. Nath S, Jana S, Pradhan M, Pal T (2010) Ligand-stabilized metal nanoparticles in organic solvent. J Colloid Interface Sci 341:333-352

21. Amendola V, Meneghetti M (2009) Laser ablation synthesis in solution and size manipulation of noble metal nanoparticles. Phys Chem Chem Phys 11:3805-3821

22. Zhang D, Gökce B, Barcikowski S (2017) Laser synthesis and processing of colloids: fundamentals and applications. Chem Rev 117:3990-4103

23. Jendrzej S, Gökce B, Epple M, Barcikowski S (2017) How size determines the value of gold: economic aspects of wet chemical and laser-based metal colloid synthesis. ChemPhysChem 18: 1012-1019

24. Streubel R, Barcikowski S, Gökce B (2016) Continuous multigram nanoparticle synthesis by high-power, highrepetition-rate ultrafast laser ablation in liquids. Opt Lett 41: 1486-1489

25. Streubel R, Bendt G, Gökce B (2016) Pilot-scale synthesis of metal nanoparticles by high-speed pulsed laser ablation in liquids. Nanotechnology 27:205602

26. Petersen S, Barcikowski S (2009) Conjugation efficiency of laserbased bioconjugation of gold nanoparticles with nucleic acids. J Phys Chem C 113:19830-19835

27. Nichols WT, Sasaki T, Koshizaki N (2006) Laser ablation of a platinum target in water. III. Laser-induced reactions. J Appl Phys 100:114911

28. Mafuné F, Kohno J-y, Takeda Y, Kondow T, Sawabe H (2001) Formation of gold nanoparticles by laser ablation in aqueous solution of surfactant. J Phys Chem B 105:5114-5120

29. Gökce B, van’t Zand DD, Menéndez-Manjón A, Barcikowski S (2015) Ripening kinetics of laser-generated plasmonic nanoparticles in different solvents. Chem Phys Lett 626:96-101

30. Rehbock C, Jakobi J, Gamrad L, Van der Meer S, Tiedemann D, Taylor U, Kues W, Rath D, Barcikowski S (2014) Current state of laser synthesis of metal and alloy nanoparticles as ligand-free reference materials for nano-toxicological assays. Beilstein $\mathrm{J}$ Nanotechnol 5:1523-1541

31. Barcikowski S, Baranowski T, Durmus Y, Wiedwald U, Gökce B (2015) Solid solution magnetic FeNi nanostrand-polymer composites by connecting-coarsening assembly. J Mater Chem C 3: 10699-10704

32. Lam J, Amans D, Chaput F, Diouf M, Ledoux G, Mary N, Masenelli-Varlot K, Motto-Ros V, Dujardin C (2014) $\gamma-\mathrm{Al}_{2} \mathrm{O}_{3}$ nanoparticles synthesised by pulsed laser ablation in liquids: a plasma analysis. Phys Chem Chem Phys 16:963-973

33. Sajti CL, Sattari R, Chichkov BN, Barcikowski S (2010) Gram scale synthesis of pure ceramic nanoparticles by laser ablation in liquid. J Phys Chem C 114:2421-2427

34. Amendola V, Amans D, Ishikawa Y, Koshizaki N, Scirè S, Compagnini G, Reichenberger S, Barcikowski S (2020) Roomtemperature laser synthesis in liquid of oxide, metal-oxide coreshells and doped oxide nanoparticles. Chem Eur J 26:9206-9242

35. Mafune F, Kohno J-y, Takeda Y, Kondow T (2003) Formation of stable platinum nanoparticles by laser ablation in water. J Phys Chem B 107:4218-4223

36. Compagnini G, Scalisi AA, Puglisi O (2003) Production of gold nanoparticles by laser ablation in liquid alkanes. J Appl Phys 94: 7874-7877

37. Werner D, Hashimoto S, Tomita T, Matsuo S, Makita Y (2008) Examination of silver nanoparticle fabrication by pulsed-laser ablation of flakes in primary alcohols. J Phys Chem C 112:1321-1329

38. Jakobi J, Menéndez-Manjón A, Chakravadhanula VSK, Kienle L, Wagener P, Barcikowski S (2011) Stoichiometry of alloy nanoparticles from laser ablation of PtIr in acetone and their 
electrophoretic deposition on PtIr electrodes. Nanotechnology 22: 145601

39. Streich C, Akkari L, Decker C, Bormann J, Rehbock C, MüllerSchiffmann A, Niemeyer FC, Nagel-Steger L, Willbold D, Sacca B (2016) Characterizing the effect of multivalent conjugates composed of $A \beta$-specific ligands and metal nanoparticles on neurotoxic fibrillar aggregation. ACS Nano 10:7582-7597

40. Zhang J, Claverie J, Chaker M, Ma D (2017) Colloidal metal nanoparticles prepared by laser ablation and their applications. ChemPhysChem 18:986-1006

41. Davodi F, Mühlhausen E, Tavakkoli M, Sainio J, Jiang H, Gökce B, Marzun G, Kallio T (2018) Catalyst support effect on the activity and durability of magnetic nanoparticles: toward design of advanced electrocatalyst for full water splitting. ACS Appl Mater Interfaces 10:31300-31311

42. Kohsakowski S, Streubel R, Radev I, Peinecke V, Barcikowski S, Marzun G, Reichenberger S (2019) First PEM fuel cell based on ligand-free, laser-generated platinum nanoparticles. Appl Surf Sci 467:486-492

43. Lee H, Reddy DA, Kim Y, Chun SY, Ma R, Kumar DP, Song JK, Kim TK (2018) Drastic improvement of 1D-CdS solar-driven photocatalytic hydrogen evolution rate by integrating with $\mathrm{NiFe}$ layered double hydroxide nanosheets synthesized by liquid-phase pulsed-laser ablation. ACS Sustain Chem Eng 6:16734-16743

44. Meng C, Lin M-C, Du X-W, Zhou Y (2019) Molybdenum disulfide modified by laser irradiation for catalyzing hydrogen evolution. ACS Sustain Chem Eng 7:6999-7003

45. Reichenberger S, Marzun G, Muhler M, Barcikowski S (2019) Perspective of surfactant-free colloidal nanoparticles in heterogeneous catalysis. ChemCatChem 11:4489-4518

46. Chen X, Meng C, Wang Y, Zhao Q, Li Y, Chen X-M, Yang D, Li Y, Zhou Y (2020) Laser-synthesized rutile TiO2 with abundant oxygen vacancies for enhanced solar water evaporation. ACS Sustain Chem Eng 8:1095-1101

47. Hupfeld T, Laumer T, Stichel T, Schuffenhauer T, Heberle J, Schmidt M, Barcikowski S, Gökce B (2018) A new approach to coat PA12 powders with laser-generated nanoparticles for selective laser sintering. Procedia CIRP 74:244-248

48. Doñate-Buendía C, Frömel F, Wilms MB, Streubel R, Tenkamp J, Hupfeld T, Nachev M, Gökce E, Weisheit A, Barcikowski S (2018) Oxide dispersion-strengthened alloys generated by laser metal deposition of laser-generated nanoparticle-metal powder composites. Mater Des 154:360-369

49. Hupfeld T, Wegner A, Blanke M, Doñate-Buendía C, Sharov V, Nieskens S, Piechotta M, Giese M, Barcikowski S, Gökce B (2020) Plasmonic seasoning: giving color to desktop laser 3D printed polymers by highly dispersed nanoparticles. Adv Optical Mat 2000473

50. De Giacomo A, Dell'Aglio M, Santagata A, Gaudiuso R, De Pascale O, Wagener P, Messina G, Compagnini G, Barcikowski S (2013) Cavitation dynamics of laser ablation of bulk and wireshaped metals in water during nanoparticles production. Phys Chem Chem Phys 15:3083-3092

51. Dell'Aglio M, De Giacomo A, Kohsakowski S, Barcikowski S, Wagener P, Santagata A (2017) Pulsed laser ablation of wireshaped target in a thin water jet: effects of plasma features and bubble dynamics on the PLAL process. J Phys D Appl Phys 50:185204

52. Kohsakowski S, Santagata A, Dell'Aglio M, de Giacomo A, Barcikowski S, Wagener P, Gökce B (2017) High productive and continuous nanoparticle fabrication by laser ablation of a wire-target in a liquid jet. Appl Surf Sci 403:487-499

53. Wagener P, Schwenke A, Chichkov BN, Barcikowski S (2010) Pulsed laser ablation of zinc in tetrahydrofuran: bypassing the cavitation bubble. J Phys Chem C 114:7618-7625

54. Jiang Y, Liu P, Liang Y, Li H, Yang G (2011) Promoting the yield of nanoparticles from laser ablation in liquid. Appl Phys A 105: 903-907
55. Bärsch N, Gatti A, Barcikowski S (2009) Improving laser ablation of zirconia by liquid films: multiple influence of liquids on surface machining and nanoparticle generation. J Laser Micro/ Nanoengineer 4:66-70

56. Barcikowski S, Menéndez-Manjón A, Chichkov B, Brikas M, Račiukaitis G (2007) Generation of nanoparticle colloids by picosecond and femtosecond laser ablations in liquid flow. Appl Phys Lett 91:083113

57. Schwenke A, Wagener P, Nolte S, Barcikowski S (2011) Influence of processing time on nanoparticle generation during picosecond-pulsed fundamental and second harmonic laser ablation of metals in tetrahydrofuran. Appl Phys A 104:77-82

58. Baladi A, Mamoory RS (2010) Investigation of different liquid media and ablation times on pulsed laser ablation synthesis of aluminum nanoparticles. Appl Surf Sci 256:7559-7564

59. Kalus M-R, Reimer V, Barcikowski S, Gökce B (2019) Discrimination of effects leading to gas formation during pulsed laser ablation in liquids. Appl Surf Sci 465:1096-1102

60. Simakin AV, Astashev ME, Baimler IV, Uvarov OV, Voronov VV, Vedunova MV, Sevost'yanov MA, Belosludtsev KN, Gudkov SV (2019) The effect of gold nanoparticle concentration and laser Fluence on the laser-induced water decomposition. J Phys Chem B 123:1869-1880

61. Barmina E, Simakin A, Shafeev G (2016) Hydrogen emission under laser exposure of colloidal solutions of nanoparticles. Chem Phys Lett 655:35-38

62. Barmina E, Simakin A, Shafeev G (2017) Balance of $\mathrm{O}_{2}$ and $\mathrm{H}_{2}$ content under laser-induced breakdown of aqueous colloidal solutions. Chem Phys Lett 678:192-195

63. Ziefuß AR, Reichenberger S, Rehbock C, Chakraborty I, Gharib M, Parak WJ, Barcikowski S (2018) Laser fragmentation of colloidal gold nanoparticles with high-intensity nanosecond pulses is driven by a single-step fragmentation mechanism with a defined Educt particle-size threshold. J Phys Chem C 122:22125-22136

64. Werner D, Furube A, Okamoto T, Hashimoto S (2011) Femtosecond laser-induced size reduction of aqueous gold nanoparticles: in situ and pump- probe spectroscopy investigations revealing coulomb explosion. J Phys Chem C 115:8503-8512

65. Werner D, Hashimoto S (2011) Improved working model for interpreting the excitation wavelength-and fluence-dependent response in pulsed laser-induced size reduction of aqueous gold nanoparticles. J Phys Chem C 115:5063-5072

66. Inasawa S, Sugiyama M, Yamaguchi Y (2005) Laser-induced shape transformation of gold nanoparticles below the melting point: the effect of surface melting. J Phys Chem B 109:3104 3111

67. Amendola V, Meneghetti M (2007) Controlled size manipulation of free gold nanoparticles by laser irradiation and their facile bioconjugation. J Mater Chem 17:4705-4710

68. Kalus M-R, Bärsch N, Streubel R, Gökce E, Barcikowski S, Gökce B (2017) How persistent microbubbles shield nanoparticle productivity in laser synthesis of colloids-quantification of their volume, dwell dynamics, and gas composition. Phys Chem Chem Phys 19:7112-7123

69. Kalus M-R, Lanyumba R, Lorenzo-Parodi N, Jochmann MA, Kerpen K, Hagemann U, Schmidt TC, Barcikowski S, Gökce B (2019) Determining the role of redox-active materials during laser-induced water decomposition. Phys Chem Chem Phys 21: 18636-18651

70. Sasaki K, Takada N (2010) Liquid-phase laser ablation. Pure Appl Chem 82:1317-1327

71. Sajti CL, Petersen S, Menéndez-Manjón A, Barcikowski S (2010) In-situ bioconjugation in stationary media and in liquid flow by femtosecond laser ablation. Appl Phys A 101:259-264 
72. Charee W, Tangwarodomnukun V (2018) Dynamic features of bubble induced by a nanosecond pulse laser in still and flowing water. Opt Laser Technol 100:230-243

73. Zhang D, Gökce B, Sommer S, Streubel R, Barcikowski S (2016) Debris-free rear-side picosecond laser ablation of thin germanium wafers in water with ethanol. Appl Surf Sci 367:222-230

74. Zhang D, Ranjan B, Tanaka T, Sugioka K (2020) Underwater persistent bubble-assisted femtosecond laser ablation for hierarchical micro/nanostructuring. Int J Extreme Manuf 2:015001

75. Hupfeld T, Laurens G, Merabia S, Barcikowski S, Gökce B, Amans D (2020) Dynamics of laser-induced cavitation bubbles at a solid-liquid interface in high viscosity and high capillary number regimes. J Appl Phys 127:044306

76. Schlichting H (1979) Boundary-Layer Theory 7ed. McGraw-Hill, New York

77. Miller CC (1924) The stokes-Einstein law for diffusion in solution. Proc R Soc Lond 106:724-749

78. Waag F, Gökce B, Barcikowski S (2019) Ablation target cooling by maximizing the nanoparticle productivity in laser synthesis of colloids. Appl Surf Sci 466:647-656

79. Genereaux RP (1930) Viscosity data in graphical form. Ind Eng Chem 22:1382-1385

80. Korson L, Drost-Hansen W, Millero FJ (1969) Viscosity of water at various temperatures. J Phys Chem 73:34-39

81. Yu W, Xie H, Li Y, Chen L, Wang Q (2011) Experimental investigation on the thermal transport properties of ethylene glycol based nanofluids containing low volume concentration diamond nanoparticles. Colloids Surf A Physicochem Eng Asp 380:1-5

82. Siems A, Weber S, Boneberg J, Plech A (2011) Thermodynamics of nanosecond nanobubble formation at laser-excited metal nanoparticles. New J Phys 13:043018

83. Dittrich S, Barcikowski S, Gökce B (2021) Plasma and nanoparticle shielding during pulsed laser ablation in liquids cause ablation efficiency decrease. Opto-Electron Adv

84. Rosenhead L (1988) Laminar boundary layers: an account of the development, structure, and stability of laminar boundary layers in incompressible fluids, together with a description of the associated experimental techniques. Dover Publications, New York

85. Cebeci T, Bradshaw P (1977) Momentum transfer in boundary layers. McGraw-Hill, New York

86. Dhawan S, Narasimha R (1958) Some properties of boundary layer flow during the transition from laminar to turbulent motion. J Fluid Mech 3:418-436

87. Rott N (1990) Note on the history of the Reynolds number. Annu Rev Fluid Mech 22:1-12

88. Prandtl L, Oswatitsch K, Wieghardt K (2013) Führer durch die Strömungslehre. Springer-Verlag, Berlin

89. Van Helden W, Van Der Geld C, Boot P (1995) Forces on bubbles growing and detaching in flow along a vertical wall. Int J Heat Mass Transf 38:2075-2088

90. Lebon M, Sebilleau J, Colin C (2018) Dynamics of growth and detachment of an isolated bubble on an inclined surface. Physical Review Fluids 3:073602

91. Chen D, Pan L-m, Ren S (2012) Prediction of bubble detachment diameter in flow boiling based on force analysis. Nucl Eng Des 243:263-271

92. Papadopoulou V, Tang M-X, Balestra C, Eckersley RJ, Karapantsios TD (2014) Circulatory bubble dynamics: from physical to biological aspects. Adv Colloid Interf Sci 206:239249

93. Mei R, Klausner J (1994) Shear lift force on spherical bubbles. Int J Heat Fluid Flow 15:62-65

94. Nahra HK, Kamotani Y (2003) Prediction of bubble diameter at detachment from a wall orifice in liquid cross-flow under reduced and normal gravity conditions. Chem Eng Sci 58:55-69
95. Kohsakowski S, Seiser F, Wiederrecht J-P, Reichenberger S, Vinnay T, Barcikowski S, Marzun G (2019) Effective size separation of laser-generated, surfactant-free nanoparticles by continuous centrifugation. Nanotechnology 31:095603

96. Bärsch N, Jakobi J, Weiler S, Barcikowski S (2009) Pure colloidal metal and ceramic nanoparticles from high-power picosecond laser ablation in water and acetone. Nanotechnology 20:445603

97. Kanitz A, Hoppius J, Gurevich E, Ostendorf A (2016) Influence of the liquid on femtosecond laser ablation of iron. Phys Procedia 83: 114-122

98. Kanitz A, Hoppius J, Fiebrandt M, Awakowicz P, Esen C, Ostendorf A, Gurevich E (2017) Impact of liquid environment on femtosecond laser ablation. Appl Phys A 123:674

99. Haiss W, Thanh NT, Aveyard J, Fernig DG (2007) Determination of size and concentration of gold nanoparticles from UV-Vis spectra. Anal Chem 79:4215-4221

100. Keene AM, Tyner KM (2011) Analytical characterization of gold nanoparticle primary particles, aggregates, agglomerates, and agglomerated aggregates. J Nanopart Res 13:3465-3481

101. Herrera AP, Resto O, Briano JG, Rinaldi C (2005) Synthesis and agglomeration of gold nanoparticles in reverse micelles. Nanotechnology 16:S618

102. Rehbock C, Merk V, Gamrad L, Streubel R, Barcikowski S (2013) Size control of laser-fabricated surfactant-free gold nanoparticles with highly diluted electrolytes and their subsequent bioconjugation. Phys Chem Chem Phys 15:3057-3067

103. Giorgetti E, Muniz-Miranda M, Marsili P, Scarpellini D, Giammanco F (2012) Stable gold nanoparticles obtained in pure acetone by laser ablation with different wavelengths. J Nanopart Res 14:648

104. Jendrzej S, Gökce B, Barcikowski S (2017) Colloidal stability of metal nanoparticles in engine oil under thermal and mechanical load. Chem Eng Technol 40:1569-1576

105. Jung HJ, Choi MY (2014) Specific solvent produces specific phase Ni nanoparticles: a pulsed laser ablation in solvents. J Phys Chem C 118:14647-14654

106. David R (2009) CRC Handbook of Chemistry and Physics. CRC Press, Florida

107. Ernst J, Spindler K, Wagner HG (1976) Untersuchungen zum thermischen Zerfall von Acetaldehyd und Aceton. Ber Bunsenges Phys Chem 80:645-650

108. Smith J, Hinshelwood CN (1944) The thermal decomposition of acetone. Proceed Royal Soc London Series A Math Phys Sci 183: 33-37

109. Watanabe T (2012) Acetone decomposition by water plasmas at atmospheric pressure. Chem Eng Sci 69:296-303

110. Dean JA (1999) Lange's handbook of chemistry. McGraw-Hill, Inc., New York

111. Kanitz A, Kalus M, Gurevich E, Ostendorf A, Barcikowski S, Amans D (2019) Review on experimental and theoretical investigations of the early stage, femtoseconds to microseconds processes during laser ablation in liquid-phase for the synthesis of colloidal nanoparticles. Plasma Sources Sci Technol 28:103001

112. Escobar-Alarcón L, Iturbe-García J, González-Zavala F, SolisCasados D, Pérez-Hernández R, Haro-Poniatowski E (2019) Hydrogen production by ultrasound assisted liquid laser ablation of Al, mg and Al-mg alloys in water. Appl Surf Sci 478:189-196

113. Evangelista JW, Avedisian CT, Tsang W (2012) Thermal and catalytic decomposition of aqueous ethylene glycol mixtures by film boiling. Int J Heat Mass Transf 55:6425-6434

Publisher's note Springer Nature remains neutral with regard to jurisdictional claims in published maps and institutional affiliations. 


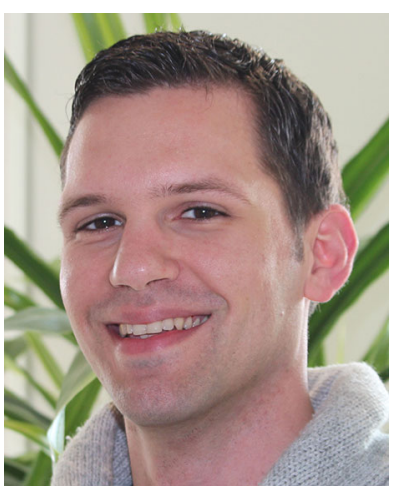

Mark-Robert Kalus studied chemistry at the University of Duisburg-Essen and graduated with a master's degree in 2015 . Afterwards, he started as an external doctoral student at Particular $\mathrm{GmbH}$ in the position as head of sales. During his doctoral studies from 2015 to 2020 at the Institute of Chemical Technology I at the University of Duisburg-Essen, he investigated the physical and chemical effects occurring during laser synthesis of colloids under the supervision of Prof. Stephan Barcikowski. In 2021, he moved to the Jülich Research Centre operating as a scientific project manager in the field of corporate development.

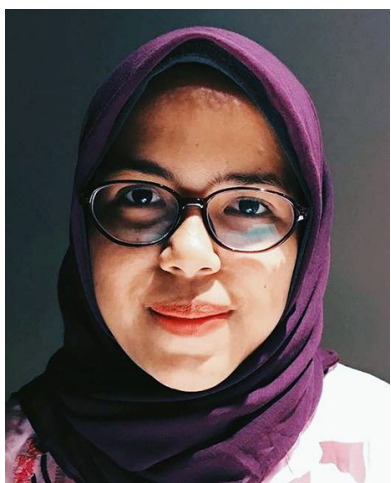

Riskyanti Lanyumba studied environmental engineering at the University of Technology in Yogyakarta, Indonesia, from 2009 to 2013, where she recieved her bachelor's degree. From 2014 to 2019 , she studied water chemistry at the University of Duisburg-Essen, where she completed her master's thesis at the Institute of Chemical Technology I, focusing on the fundamentals of laser synthesis of colloids.

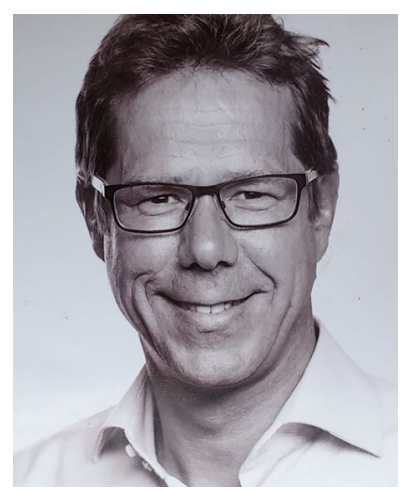

Stephan Barcikowski studied chemistry in Braunschweig and Hannover, and received his $\mathrm{PhD}$ in Mechanical Engineering (Materials). At the Laser Zentrum Hannover, Barcikowski built up the Nanomaterials group, and later led the institute's Materials Processing Department. In 2010, he cofounded the company Particular $\mathrm{GmbH}$. Since 2011, he chairs the Institute of Chemical Technology I at the University of DuisburgEssen. Stephan Barcikowski has more than 250 reviewed papers and patent files, cited over 7,000 times. He launched the scientific video channel 'nanofunction' on youtube with more than 78,000 viewings. He serves editing the Journal Applied Surface Science and guest editing several Journals.

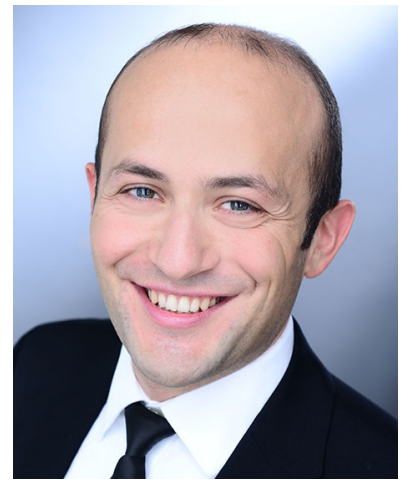

Bilal Gökce studied physics and received his "Diplom" degree from RWTH Aachen University in 2008. From 2007 to 2009, he worked on laser material processing of metals at Fraunhofer Institute for Laser Technology. During his Ph.D. studies at North Carolina State University from 2009 to 2012, he studied fundamental phenomena in condensed matter through ultrafast laser spectroscopy. Afterwards, he worked as a researcher on laser applications for semiconductors at the company T-Systems International. In 2014 he joined the Faculty of Chemistry at the University of Duisburg-Essen as a group leader to establish his own group focusing on functionalization of laser-generated nanoparticles and developing materials for additive manufacturing. 2021 he became a full professor at the University of Wuppertal and since then heads the Chair of Materials Science and Additive Manufacturing. 